\title{
Mobile Technology and Studies on Transport Behavior: A Literature Analysis, Integrated Research Model, and Future Research Agenda
}

\author{
Yan Sun $\mathbb{D}^{\mathbb{D}},{ }^{1}$ Chengxi Liu $\mathbb{D}^{\mathrm{D}},{ }^{2}$ and Chen Zhang $\mathbb{D}^{3}$ \\ ${ }^{1}$ School of Management Science and Engineering, Shandong University of Finance and Economics, Jinan 250014, \\ Shandong Province, China \\ ${ }^{2}$ Swedish National Road and Transport Research Institute, Linköping 58330, Sweden \\ ${ }^{3}$ School of Media and Design, Beijing Technology and Business University, Beijing 102488, China
}

Correspondence should be addressed to Chen Zhang; chenzh@btbu.edu.cn

Received 1 September 2021; Accepted 30 September 2021; Published 25 October 2021

Academic Editor: Cristina Cristina Manresa-Yee

Copyright ( 2021 Yan Sun et al. This is an open access article distributed under the Creative Commons Attribution License, which permits unrestricted use, distribution, and reproduction in any medium, provided the original work is properly cited.

\begin{abstract}
The prevalence of mobile technology has been significant in transport research. Despite a growing application spectrum of smartphone uses and interests in mobility inference, little effort has been put into discussing theories, models, and research topics based on a systematic study of scholarly sources rooted in the interdisciplinary area of mobile technology and transport. Therefore, a timely and comprehensive synthesis of the current state of research is deemed to be required. A literature analysis, following PRISMA guidelines, aims to identify the successful development and implementation of the mobile technology that can be employed for behavior studies in transport. A review of the Web of Science Core Collections, JSTOR and SAGE databases, is performed. A rigorous screening process is used to collect key articles to construct the general image of existing knowledge. In addition, this study suggests an integrated research model to summarize how previous studies attain behavioral outcomes and a research agenda to identify unresolved research questions that future research can address. Two hundred fourty-eight papers meet the inclusion criteria. This study demonstrates that mobile technology is helpful for a better understanding of the various types of transport behaviors. They can be categorized according to their system designs and research topics: (1) Smartphone apps in sustainable transport and travel planning were studied in a remarkable collection of articles. (2) As individual's mobility was under question, cellular signaling data were prominent for the formulation of analytical models. (3) CDRs, WiFi, and GPS data have increasingly been used, but the share of the modeling techniques for all mobile information systems has remained low. It shows that system designers could supply more desirable and appealing features in most areas. However, applications for the movement of goods are limited, although freighting has moved toward digitalization.
\end{abstract}

\section{Introduction}

Mobile technology is one of many growing topics in mobility inference. This trend is driven by digitalized transport in the visualization and capitalization of Big Data [1]. While mobile technology has been referred to in various contexts, in this paper, we define it within the transport sector as the "employment of smartphones and expanding cellular networks to integrate and influence mobility." Focusing on the current state of research, the research scope of mobile technology in transport behavior studies could be mobile data techniques and the utilization of smartphone apps. Mobile phone data techniques revolve around the collection and analysis of information that is sent or received from a device in a cellular network. In this respect, call detail records (CDRs) [2], Global Positioning System (GPS)/global navigation satellite system (GNSS) data [3], and cellular signals [4] are the most researched types of mobile data. The utilization of smartphone apps addresses the interface design [5], user 
adoption [6], and behavioral outcome [7], such as a mode switch and user response to real-time information, within the transport system.

On the contrary, mobile phone data hold the promise of helping produce accurate transport measures and representative models of human behavior and a new era for activity-based modeling [8]. This is considered a complement to traditional surveying, which is considered expensive to conduct and unsuitable for capturing spatial mobility patterns that have a high level of informality [9]. To understand individual mobility patterns, there is a need to develop efficient algorithms for various travel behavior inferences such as transport mode detection, travel route mapmatching and analysis in tandem with the spatial-temporal organization of activities. To support this development, it is essential to know what types of behavior studies within the transport sector can be performed and what types of mobile phone data are needed for these studies. On the contrary, mobile technology also benefits from an understanding of individual mobility patterns because the providers are increasingly utilizing their collected transport measures to customize their individualized service. To this purpose, it becomes vital that the transport measures can be transformed into useful behavioral preferences, which rely heavily on the algorithms designed for travel behavior inference.

Most roles of existing technologies can be fulfilled by smartphone apps designed and implemented in a usercentric manner. The ever-increasing proportion of users who have access to mobile devices creates an opportunity to establish previously unavailable data sets. There has been little established about what opportunities location data collected from mobile technology provide for transport behavior research, how riders' transport behaviors are affected by mobile phone use, what features and contents of mobile information systems they adopt, and which heuristics approach is available with mobile phone data.

The promising impact of mobile technologies in transport was showcased at the beginning of the 21st century [10]; however, it remains unknown what type of mobile technology can be used to analyze, influence, and collect mobility. Literature reviews have been conducted with an explicit focus on a causal relationship that will benefit the mobility of passengers and goods. However, previous literature reviews have been limited in at least one of the following aspects: (1) reviews usually synthesize contributions by analyzing a single perspective, such as transport surveying; a single focused issue, primarily sustainability, or a single transport mode; (2) most reviews have examined papers published before 2015; and (3) literature analysis of papers on smartphone apps has become scarce in recent years.

This paper proposes a literature study to reflect the progress over the past two decades in the interdisciplinary research area of mobile technology and transport behavior understanding. We first reviewed previous works and outlined their categories. In the next step, each of the paper was scrutinized to assess the most widely applied mobile technology in transport. An integrated research model was proposed to conceptualize the corresponding research process as a guideline for creating a practical and empirically grounded understanding of mobility in the digital age. The research agenda presented in this paper could serve as the guideline of crucial steps for a sustained research endeavor. The remainder of this study is arranged as follows: the methodology of the literature analysis on mobile technology in transport behavior studies and its coverage is summarized in Section 2. The results for analyzing the state-of-the-art is then detailed in Section 3, followed by its critical discussion with the common terms and challenges identified from the literature in Section 4. A discussion on the future research agenda and recommendations for continued researches concludes this paper.

\section{Methods}

This literature study focuses on the identification of mobile technology to provide critical insights and a meaningful inference of mobility. This is the lens through which the articles were identified, reviewed, and understood. Given the growing number of studies published over the past two decades, it is urgent to explore the application and methodological diversity in this field to provide a forward-looking of digitalized transport. The objective of this literature study is to provide a critical discussion of trends, an integrated research model and a future research agenda to answer the following research question:

(i) What are the successful development and implementation of mobile technologies in transport behavior studies?

The literature analysis was conducted based on the Preferred Reporting Items for Systematic Reviews and MetaAnalysis (PRISMA) guidelines, as shown in Figure 1. The identification of suitable publications was performed by searching the Web of Science Core Collection, SAGE Journals, and JSTOR databases. All of these databases cover top-notch journal articles, laying the groundwork of sufficient literature analysis. The search identified papers published between 2000 and 2020 during the duration of the substantial growth of interdisciplinary research interests on mobile technology in transport.

2.1. Search Terms. The individual paper reviewer selected keywords to ensure a comprehensive and broad coverage of transport behavior research, as shown in Table 1. Provided indexing rules in databases, search queries on research scopes and context specificality were combined, with the terms "app," "digitali*," and "mobile application" focusing on the usage of mobile phones and relevant technologies and the terms of "mobilit*," "tourism," "supply SAME chain," and so forth addressing the core activities.

2.2. Article Inclusion Criteria. Based on an individual paper examination process, inclusion criteria with regard to content and research topic were applied to construct the sample. First, included papers must be peer-reviewed articles written in English. Second, the contribution must be 


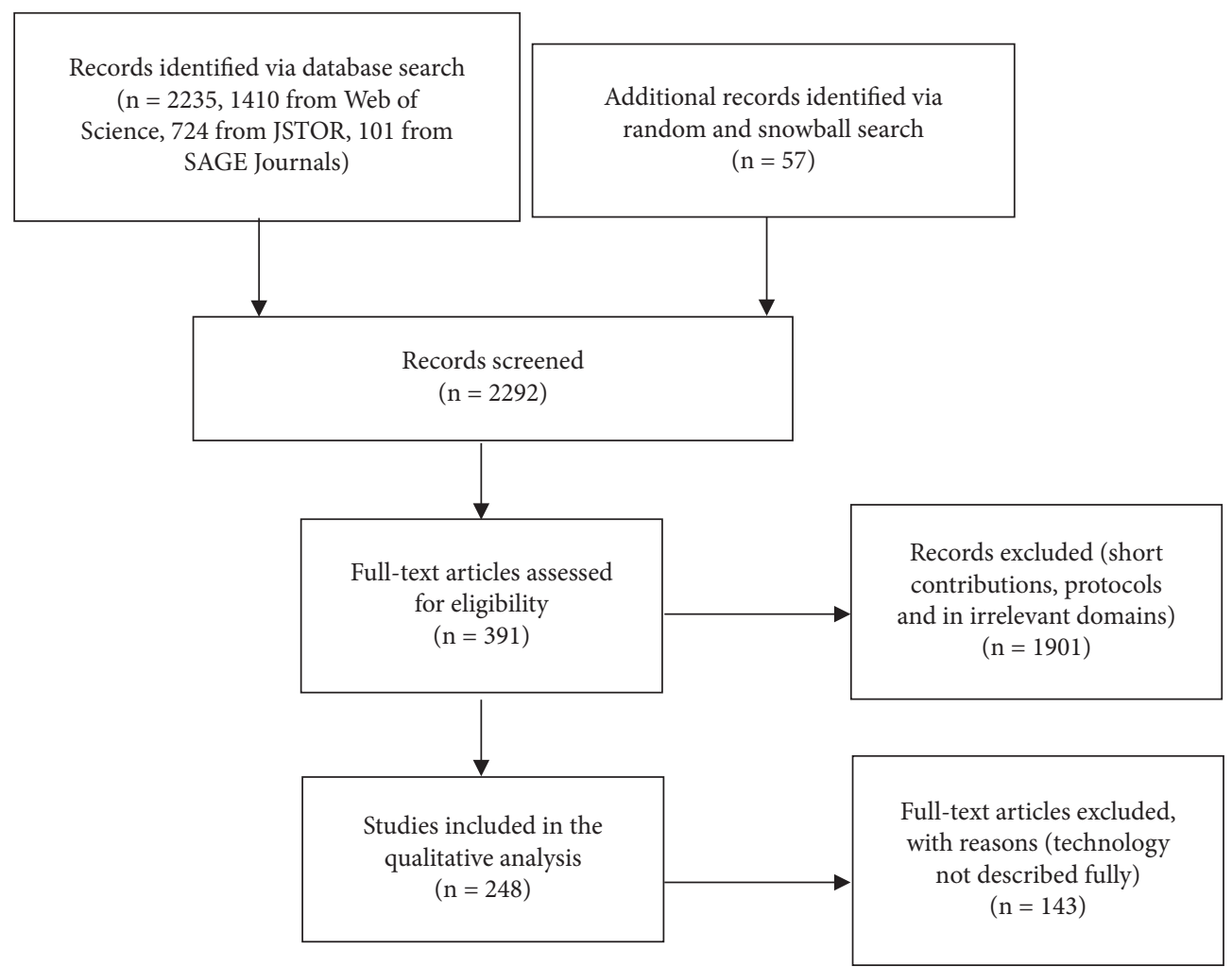

FIgURE 1: PRISMA flow diagram of the assessment procedure and results: number of records included and excluded and reasons.

TABLE 1: Queries employed for the databases.

\begin{tabular}{|c|c|c|c|}
\hline Database & Queries for passenger transport studies & Queries for tourism studies & Queries for freighting transport studies \\
\hline $\begin{array}{l}\text { Web of } \\
\text { Science core } \\
\text { collection }\end{array}$ & $\begin{array}{c}\mathrm{TI}=\text { (“app" OR “digitali*” OR “mobile } \\
\text { application*” OR “mobile*”) AND } \\
\text { (TS = ("transport" OR “mobilit*” OR } \\
\text { "modal” OR “commut"”) ) AND } \\
\text { (TS = "behavio*”) }\end{array}$ & $\begin{array}{c}\text { TI = (“app" OR "digitali*” OR “mobile } \\
\text { application"” OR “mobile*”) AND } \\
(\mathrm{TS}=(\text { "travel" OR "touris*”)) AND } \\
(\mathrm{TS}=\text { "behavio*”) }\end{array}$ & 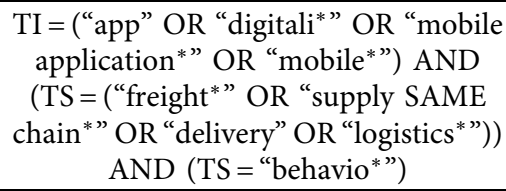 \\
\hline JSTOR & $\begin{array}{l}\text { ti:(“app” OR “digitali"”OR “mobile } \\
\text { application" OR "mobile") AND } \\
\text { ("behavio*” OR "passenger SAME } \\
\text { transport" OR "flow" OR“accessibility") }\end{array}$ & $\begin{array}{l}\text { ti:(“app" OR “digitali*”OR “mobile } \\
\text { application" OR “mobile*”) AND } \\
\text { ("behavio*” OR “tourism" OR "tourist" } \\
\text { OR "trip planning") }\end{array}$ & $\begin{array}{c}\text { ti:(“app" OR “digitali*”OR “mobile } \\
\text { application" OR "mobile*”) AND } \\
\text { ("behavio*” OR "logistics" OR } \\
\text { "freight") }\end{array}$ \\
\hline $\begin{array}{l}\text { SAGE } \\
\text { journals }\end{array}$ & $\begin{array}{c}\text { For [[title app] OR [title digitali*] OR } \\
\text { [title mobile application] OR [title } \\
\text { mobile*]] AND [[keywords passenger] } \\
\text { OR [keywords human]] AND } \\
\text { [[keywords mobility] OR [keywords } \\
\text { accessibility]] }\end{array}$ & 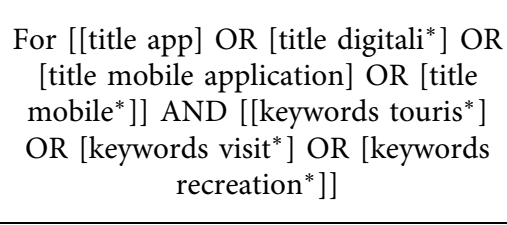 & $\begin{array}{c}\text { For [[title app] OR [title digitali*] OR } \\
\text { [title mobile application] OR [title } \\
\text { mobile* }] \text { AND [[keywords freight* }^{*} \\
\text { OR [keywords logistics*] OR } \\
\text { [keywords delivery] OR [keywords } \\
\text { supply chain]] }\end{array}$ \\
\hline
\end{tabular}

concerned with the actual measurement of transport behavior changes or attitudinal modifications toward technology adoption. After fulfilling these preconditions, they were included in the qualitative analysis only if they met one of the following criteria:

(1) Problem-Solving Paper. The research employed a type of mobile phones, mobility collectors, or any smartphone apps. Articles on smartphone apps showcased their system and interface designs.

(2) Review and Synthesis Paper. The research records the main methodological points of the existing deployment of mobile phones in transport behavior studies, followed by a summary and evaluation of the changes resulting from the revolutionary mobile information and communication technologies.

2.3. Literature Mapping. To understand development flows, research trends were streamlined through networking visualizations in CiteSpace, which identifies networks, emerging tendencies, collections and collaborations among the scientific literature [11]. It is hard to determine the effects of the informative visualization that could be delivered by a given configuration because the clarity and complexity of diagrams depend on the network size in CiteSpace. 
Therefore, we selected the composition that realizes the best balance between legibility and visualization details. Citation frequency determines the sizes of labels and nodes. The larger a node and label, the more cited the reference. Links and notes indicate the first time that two references were cocited and the year interval, respectively.

\section{Results}

The records for the qualitative analysis were identified using the PRISMA procedure. There were 248 total scientific articles, among which 142 revolved around the effectiveness of smartphone apps, 90 addressed mobile phone data, and 16 performed synthesis and review of existing literature, as listed in Table 2.

The screening process derived the aims of transport behavior studies integrating mobile technology. The following research purposes are identified: mobility pattern analysis, technology adoption, policy impact assessment, and advances in methodology and technology. The contributions targeting mobility pattern analysis emphasize the collection, visualization, and prediction of selected mobility indicators with a strong reliance on mobile Big Data. The category of technology adoption includes articles working on successful communication for user engagement influenced by design factors, for example, values, usefulness, and appearances. Policy studies handle the impact of the proposed technological development by measuring individual behavioral outcomes in the transport area. Advances in methodology promote the scientific development of modeling and analytics using mobile phone data.

3.1. Mobile Technology in Transport Behavior Studies: A Review. Smartphone apps have been the most extensively used end-to-end solution for mobile device and affect an individual's mobility relationship, as shown in Figure 2. In particular, such apps are a promising tool for route planning and trip organization. Even in early successful app implementations, mobile phones rendered real-time and localized transport information. Watkins et al. investigated the impact of real-time data on transit riders through the convenience of an information system [12], providing evidence that realtime mobile information reduces the perceived and actual wait time. Tsirimpa [13] presented a case study for the Athens Metropolitan Area, Greece, in 2009 to explore realtime travel information from mobile devices. Both individuals' attitudes and the effect of information acquisition on activity rescheduling were considered. To quantify the primary impacts, statistical methods could infer riders' characteristics, and studies could estimate choice models [14] and generalized estimating equations [15] based on a travel choice survey of smartphone users.

Using innovative smartphone apps, riders are informed of the positive consequences of taking a given trip with more sustainable options. Tailored messages and recommendations transformed the way mobility approaches environmental stewardship. Meireles and Riberiro's study showed that more than $60 \%$ of nonregular cyclists at the regional level considered smartphone apps to lead more people to use bicycles [164]. Cycling mobile apps should prioritize route calculation and location-based services associated with the built environment, according to the questionnaire. Asitha and Khoo found timing information to be the most critical factor in travel decisions [165]. A linear relationship for information provision with the usage of smartphone apps contributed to the overall intervention of transport mode choice. In addition, personalized campaigns promote sustainable transport, as showcased by di Teulada and Meloni's research on the steering role of a smartphone app in carrying out a voluntary travel behavior change program [166].

Smartphone apps collected detailed user data regardless of transport mode and built environment, unlike traditional surveys. It also facilitated the interaction of data from sensors and end users to establish real-time calibration advantages. Faghih Imani et al. identified trips based on appbased data collection and algorithms [16]. The travel mode for trip legs and purpose could be recorded with proper interface design and streamlined process quality assessment. Lynch et al. [109], via a smartphone-based household travel survey, showed methods for increasing the representation of hear-to-reach riders. Vich et al. analyzed the factors that influenced the extent of activity spaces of suburban commuters at the individual and environmental levels using data from smartphone apps, in which the effectiveness of the calculation method for measuring activity spaces was explored [17]. The results indicated that spatiotemporal and socioeconomic factors were strong determinants of the activity space geography.

Research on smartphone apps and transport also takes technology adoption as a central topic. Park and Ohm designed an integrated research model to analyze the behavioral intention to employ mobile map services [110]. In this study, users' employment of mobile map services was decided by the satisfaction with and perceived usefulness of those services. The moderating effect of mobile usage was evident on behavioral intention and facilitation conditions [111]. Mallat et al. proposed a technology adoption model and trust theories to explore users' intention to adopt mobile ticketing services in public transport [112]. Mobility, availability of other alternatives, and time pressure in the service usage situation corresponded to the adoption decision. Apps were also used in freighting. By surveying 217 adopters, Schoenherr showed that mobile devices and applications help decision-makers rapidly realize and respond to operational circumstances in supply chains [154].

Smartphone apps have been used directly to promote safe transport for pedestrians and individuals' health and well-being. Taking advantage of mobile devices' functionality for integrating personal behavior models, smartphones are increasingly valuable tools for activity-based transport. Bopp et al. found that active travel is influenced by time, distance from the destination, and health concerns [192]. Route planning and projected time for a commute are the most frequently requested app features. Rezae et al. evaluated the motivational effect of an assistive transport app to support autistic mobility [193], which requires crowd information and accessible scenarios for riding public 
TABLE 2: Catalog of reviewed papers.

\begin{tabular}{|c|c|c|c|c|c|c|c|}
\hline $\begin{array}{l}\text { Focused } \\
\text { research issue }\end{array}$ & & $\begin{array}{l}\text { Research } \\
\text { scope }\end{array}$ & $\begin{array}{c}\text { Mobile date } \\
\text { category }\end{array}$ & Context & Transport mode & $\begin{array}{c}\text { Geographical } \\
\text { placement of } \\
\text { activities } \\
\end{array}$ & $\begin{array}{c}\text { Temporal } \\
\text { placement of } \\
\text { activities } \\
\end{array}$ \\
\hline $\begin{array}{l}\text { Route or mode } \\
\text { selection }\end{array}$ & $\begin{array}{c}{[2-4,10,12-27]} \\
{[28-51][52-72]} \\
{[73-108]}\end{array}$ & $\begin{array}{l}\text { App (45); } \\
\text { data } \\
\text { system } \\
(57)\end{array}$ & $\begin{array}{l}\text { Cellular signal } \\
\text { (10); CDRs (21); } \\
\text { GPS (21); WiFi } \\
\text { (7); accelerator } \\
\text { (4); GNSS (1); } \\
\text { Internet traffic } \\
\text { (1); usage data (2) }\end{array}$ & $\begin{array}{c}\text { Passenger } \\
\text { transport } \\
\text { (84); tourism } \\
\text { (16) }\end{array}$ & $\begin{array}{l}\text { Automobile (34); } \\
\text { public transport } \\
(36) \text {; train }(12) ; \\
\text { air transport (1); } \\
\text { walking (24); } \\
\text { cycling (17) }\end{array}$ & $\begin{array}{c}\text { Indoor (2); local } \\
(24) ; \\
\text { metropolitan } \\
(49) ; \text { regional } \\
(12) ; \text { national } \\
(13)\end{array}$ & $\begin{array}{l}\text { Single trip } \\
\text { (13); Same- } \\
\text { day (11); day- } \\
\text { to-day (54) }\end{array}$ \\
\hline $\begin{array}{l}\text { Smartphone } \\
\text { usage }\end{array}$ & $\begin{array}{c}{[5,7,109-116]} \\
{[117-133]} \\
{[134-161]} \\
{[162,163]}\end{array}$ & $\begin{array}{l}\text { App (49); } \\
\quad \text { data } \\
\text { system (8) }\end{array}$ & $\begin{array}{c}\text { GPS (3); Internet } \\
\text { traffic (1); user } \\
\text { data (6) }\end{array}$ & $\begin{array}{c}\text { Passenger } \\
\text { transport } \\
(28) ; \text { tourism } \\
\text { (16) }\end{array}$ & $\begin{array}{l}\text { Automobile (34); } \\
\text { public transport } \\
(36) \text {; train }(12) ; \\
\text { air transport (1); } \\
\text { walking (24); } \\
\text { cycling (7) }\end{array}$ & $\begin{array}{c}\text { Indoor (2); local } \\
(24) ; \\
\text { metropolitan } \\
(49) ; \text { regional } \\
(12) ; \text { national } \\
(13) \\
\end{array}$ & $\begin{array}{l}\text { Single trip } \\
\text { (13); Same- } \\
\text { day (11); day- } \\
\text { to-day (54) }\end{array}$ \\
\hline $\begin{array}{l}\text { Sustainable } \\
\text { mobility }\end{array}$ & [164-191] & $\begin{array}{l}\text { App (18); } \\
\text { data } \\
\text { system } \\
(10)\end{array}$ & $\begin{array}{c}\text { GPS (5); } \\
\text { accelerator (2); } \\
\text { usage data (3) }\end{array}$ & $\begin{array}{c}\text { Passenger } \\
\text { transport } \\
(26) \text {; tourism } \\
(1) \text {; freight } \\
\text { transport (1) }\end{array}$ & $\begin{array}{l}\text { Automobile (23); } \\
\text { public transport } \\
\text { (18); train (7); air } \\
\text { transport (1); } \\
\text { walking (15); } \\
\text { cycling (19) }\end{array}$ & $\begin{array}{c}\text { Local (8); } \\
\text { metropolitan } \\
\text { (14); regional (3); } \\
\text { national (3) }\end{array}$ & $\begin{array}{l}\text { Single trip } \\
\text { (5); Same- } \\
\text { day (1); day- } \\
\text { to-day (15) }\end{array}$ \\
\hline Health & [192-203] & $\begin{array}{l}\text { App (4); } \\
\text { data } \\
\text { system (6) }\end{array}$ & $\begin{array}{c}\text { GPS (3); } \\
\text { accelerator (2); } \\
\text { physiology (1) }\end{array}$ & $\begin{array}{l}\text { Passenger } \\
\text { transport } \\
(10)\end{array}$ & $\begin{array}{c}\text { Automobile (2); } \\
\text { public transport } \\
\text { (2); walking (2); } \\
\text { cycling (3) }\end{array}$ & $\begin{array}{c}\text { Local (4); } \\
\text { metropolitan (3); } \\
\text { regional }(1) ; \\
\text { national }(1)\end{array}$ & $\begin{array}{l}\text { Single trip } \\
\text { (5); Same- } \\
\text { day (1); day- } \\
\text { to-day (15) }\end{array}$ \\
\hline Safety & [204-213] & $\begin{array}{l}\text { App (8); } \\
\text { data } \\
\text { system (2) }\end{array}$ & & $\begin{array}{c}\text { Passenger } \\
\text { transport } \\
(26) \text {; tourism } \\
(1) \text {; freight } \\
\text { transport (1) }\end{array}$ & $\begin{array}{l}\text { Automobile (23); } \\
\text { public transport } \\
\text { (18); train (7); air } \\
\text { transport (1); } \\
\text { walking (15); } \\
\text { cycling (19) }\end{array}$ & $\begin{array}{c}\text { Local (8); } \\
\text { metropolitan } \\
(14) ; \text { regional (3); } \\
\text { national (3) }\end{array}$ & $\begin{array}{l}\text { Single trip } \\
\text { (1); Same- } \\
\text { day (2); day- } \\
\text { to-day (4) }\end{array}$ \\
\hline $\begin{array}{l}\text { General } \\
\text { transport } \\
\text { behavior or } \\
\text { experience }\end{array}$ & {$[9,214-232]$} & $\begin{array}{l}\text { App (10); } \\
\text { data } \\
\text { system } \\
(10)\end{array}$ & $\begin{array}{l}\text { Cellular signal } \\
\text { (2); GPS (3); WiFi } \\
\text { (1); accelerator (1) }\end{array}$ & $\begin{array}{c}\text { Passenger } \\
\text { transport } \\
(17) ; \text { tourism } \\
\text { (2) }\end{array}$ & $\begin{array}{l}\text { Automobile (6); } \\
\text { public transport } \\
\text { (7); train (1); air } \\
\text { transport (1); } \\
\text { walking (7); } \\
\text { cycling (6) }\end{array}$ & $\begin{array}{c}\text { Indoor (1); local } \\
\text { (4); metropolitan } \\
\text { (10); regional (2); } \\
\text { national (1) }\end{array}$ & $\begin{array}{l}\text { Single trip } \\
\text { (3); Same- } \\
\text { day (4); day- } \\
\text { to-day (9) }\end{array}$ \\
\hline Misc. & [233-237] & $\begin{array}{c}\text { Data } \\
\text { system (2) }\end{array}$ & Cellular signal (1) & $\begin{array}{l}\text { Tourism (1); } \\
\text { freight } \\
\text { transport (2) }\end{array}$ & Walking (1) & Metropolitan (2) & \\
\hline
\end{tabular}

Synthesis/ review

$[108,238-252]$

transport. To detect negative emotions during driving, smartphone apps have been developed to quantify raw physiological data as valid measures of stress [194]. Weber et al. elucidated the effects of riders engaging via smartphone apps and their activity registration to confirm the growing interest in bicycle ridership via digital encouragement [195].

3.2. Mobile Phone Data. Following the screening process, we identified the following types of mobile phone data: cellular signals, CDRs, global positioning system data/global navigation satellite system data, mosion sensor data, and usage data. In transport behavior studies, the cellular signal data set consists of anonymous mobile tracking record collected from mobile operators. A CDR is produced when a device connects to the cellular network for events, such as calling, texting, handover, and location update. Global positioning system data are the autonomous related geospatial and time information gathered from satellite positioning. Motion sensor data account for the physical behavior of mobile devices. User data reflect analytics, trends, and usage information generated and owned by riders.

3.2.1. Cellular Signals. Thanks to the indispensable usage of mobile phones in daily life activities, cellular signaling data enable transport behavior studies to expand spatial and temporal coverage. Cellular signal data could be useful in transport demand modeling, a discovery from Caceres et al.'s work [18]. The data constructed origination- 


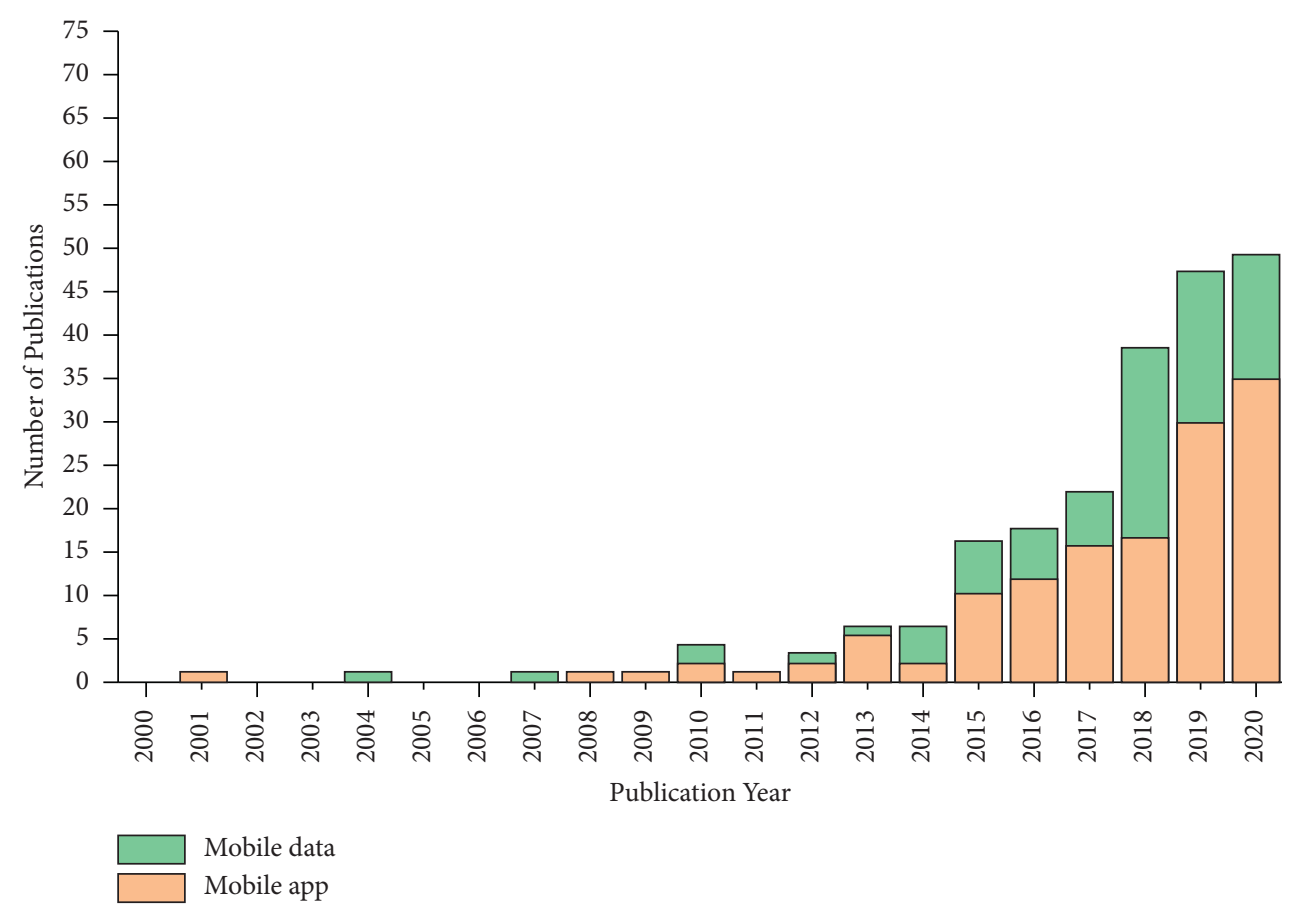

FIGURE 2: Research scope of the studies on mobile technology in transport behavior.

destination matrices covering most human movements to visualize regional mobility patterns with a low granularity of the zoning system. Asakura and Hato focused on a tracking survey method for individual travel behavior in an urban area using the cellular phone system [92]. This made tracking metropolitan mobility much easier. Fine-grained transport mode information could be extracted by applying supervised methods to cellular signaling data sets, according to Chin et al.'s study [4]. Passenger behavior during air transport could be realized by leveraging records from the major communication carriers [215]. The distribution of passenger flows, aggregated from mobile data, is consistent with those from traditional methods, which sheds light on future developments of complex transport systems.

3.2.2. CDRs. CDRs offer diaries of phone activity. They are primarily used for business billing purposes. Owing to the facilitated access to these data sources, CDRs could be a reliable source of illustrating points of interest and keeping track of phone system usage. As a complement to traditional transport surveys, Phithakkitnukoon et al. proposed a detection algorithm to process CRD in their mode choice study [19]. This study found that social ties determine ridership among public transit and automobiles. By identifying temporal regularity in human urban mobility, call activity volume gathered from mobile networks could estimate the aggregated distribution of the metropolitan population over time, as suggested by Sevtsuk and Ratti's research [20]. It was not just aggregation-based on CDRs; Calabrese et al. formulated a multivariate regression model to predict human mobility [21], indicating the value of such data sources as representative of individual mobility as well as for understanding intraurban variation. In addition to GIS data, CDRs can further be added with geographical references-Williams et al. designed six novel measures of mobility that integrate both mobile phone records and detailed GIS data to analyze the spatial nature of human mobility [22], clarified the influence of human mobility on microlevel human behavior and well-being and macrolevel social organization and change.

3.2.3. GPS/GNSS Data. GPS/GNSS data have been used to investigate spatial mobility with a high zoning resolution and low levels of wear-related concerns. It is thus a wellsuited data collection method for the continuous recording of time series. In particular, it is possible to portray the structure of habits in mobility. Supported by such data, planners can identify additional, unplanned routes in parallel to the utilization of major road infrastructure, according to Joseph et al.'s study [9]. Bernardi et al. focused on the relationship between cyclists' route choices and various attributes of the transport network by using GPS traces [23]. This research detected some rare traits of cyclists to repeat preferred trips via the shortest route. Toader et al. used geospatial Big Data to investigate collaborative mobility [24]. With the help of GPS traces, the opportunities and behavioral changes for shared mobility solutions can be recognized automatically. A powerful analytical approach for urban transport could be developed into the incorporation of GPS and transactional data, as demonstrated by Lu et al. [25]. To summarize what has been stated thus far, the use of GPS data is not limited to mobility inference but serves navigation, localization, and ubiquitous computing systems. 
3.2.4. Motion Sensor Data. In addition to GPS component, various sensors, such as accelerometers, gyroscopes, and magnetometers, are currently built into smartphones to detect changes and generate data by measuring device movements and aspects of the environment. Jimenez et al. used smartphone sensor data to estimate real-time energy consumption [167]. The results showed that the model's accuracy could be improved by including the classification of the driving style. Kinematic changes recorded by smartphone sensors can sufficiently represent passenger ride comfort as a key factor of service quality [196]. In addition, pervasive sensing is becoming accepted in the transport sector. This point is best illustrated by Zhou, Yu, and Sullivan's research on real-time control, which built a chained random forest model to transform smartphone data into information on various travel modes [72]. This delivered good performance in both indoor and outdoor environments with $93.8 \%$ overall accuracy.

3.2.5. Usage Data. Researchers have begun to collect various types of user behavior data to figure out design issues when technology adoption is mentioned. They are deployed to improve user authentication, create user interfaces, and address the needs of riders. Semanjski et al. developed a research model based on support vector machines to understand the role of the spatial context of human movements from mobile-sensed Big Data [26]. The results demonstrated a success rate of $94 \%$ achieved by the proposed model. Louveton et al. developed a car-following task within a driving simulator environment to study driver-mobile interactions [114]. Common tasks, that is, binary decision, list selection, and slide bar, were evaluated by the authors. Suh et al. investigated the last-mile delivery problem based on environmental impacts and discussed the use of mobileenabled social networks [168]. Cottrill et al. presented the design, development, and implementation of a smartphonebased prompted-recall travel survey [115]. They found that a clear workflow and simple user interaction are essential to maintain participation rates.

3.3. Analysis of Trends. The collection and analysis of GPS/ GNSS data have been the most prominent methods for understanding transport behaviors. Between 2000 and 2010, as shown in Figure 3, there were few studies using mobile phone data. In 2004, mobile technology in transport behavior studies started using cellular signals. Again, the emerging role of cellular signals is observed between 2015 and 2020. The presence of CDRs is evident in mobility studies during all time periods. The distribution of data types among across periods presents an increasing diversity of mobile techniques in recent years. In line with diversified methods over the past 5 years is the specific mobile phone data that was not stated with regard to information and characteristics. These new data from mobile technology are categorized as miscellaneous.

Mobility flow analysis and technology adoption were the predominant research questions addressed in all periods, as shown in Figure 4. Most studies addressed the critical process that guarantees riders the necessary acquisition of services, information, and transport products between 2010 and 2015. Following this, mobile phones are increasingly used for mobility analysis. This is a promising research theme allowing humanitarian interventions to better understand population movement in urban areas. Articles addressing methodological and technical aspects of mobile phone use and related approaches to scientific developments have constituted a large proportion of all research efforts in the recent years. However, polity assessment and evaluation remain largely underexplored in the literature compared with other research streams.

Passenger transport was the most common sector studied, as shown in Figure 5. The research interest spearheaded in 2010, after which the application of mobile phones in the tourism sector addressed technology adoption and travel experience. Despite a diversified landscape of research themes, in 2020, forty-six of 59 articles touched upon behaviors in passenger transport, and only thirteen articles were related to tourism and freight transport. Currently, the ability to collect mobility data from smartphones, improved system design, and utilization of pervasive strategies was the main driver of digital adoption among riders.

Compared with passenger transport and tourism, we identified few publications on freight transport, covered by a limited number of articles during the span of the studied period; however, emerging freight apps afford a mechanism of consolidation and transshipment on the mobile Internet [253]. There is an ever-growing scientific research effort in mobile ICT, on-time delivery performance, and greater visibility into the movement of goods [233]. However, their behavioral consequences of implementing sustainable processes have not been thoroughly studied. Thus, the intersection of mobile technology and freight transport is still quite innovative and underexplored.

The literature study categorized geographical placements of travels that include certain areas at the within-building, local, metropolitan, regional, and national levels, as Figure 6 shows the number of articles published during the study period. Research in this field has been conducted at the national level with nationally important mobility characteristics. 2019 saw the most systematic studies at the national level after a steady growth of publications over the years. Mobile-based techniques addressing regional mobility issues were rarely studied before 2016 but have increased in recent years. In addition, a number of studies have demonstrated that mobile phone use has a clear influence on transport behavior at the local scale.

Using mobile technology to study transport behavior in metropolitan areas touched upon the simultaneously growing demands of mobility and changes in riders' expectations in urban systems. This literature study observed that a continuously growing number of studies are performed at a macro level to introduce innovative mobility inference based on data collected from a large number of inhabitants as well as device holders. This contributed to the potential transformation of mobility in the investigated area through the integrated design, application, and analytics of smartphone apps. 


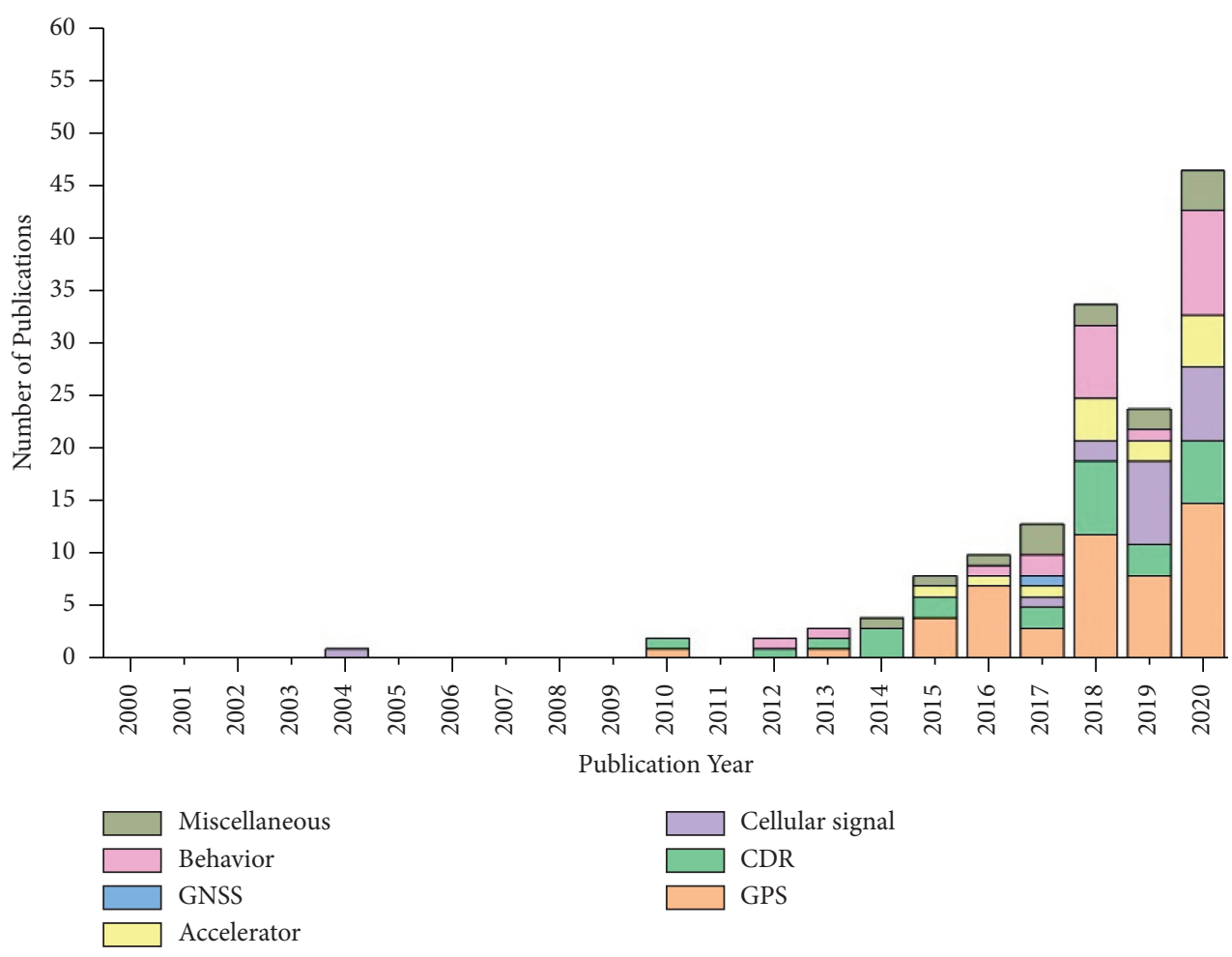

FIgURE 3: Categories of data for the study of mobile technology in transport behavior.

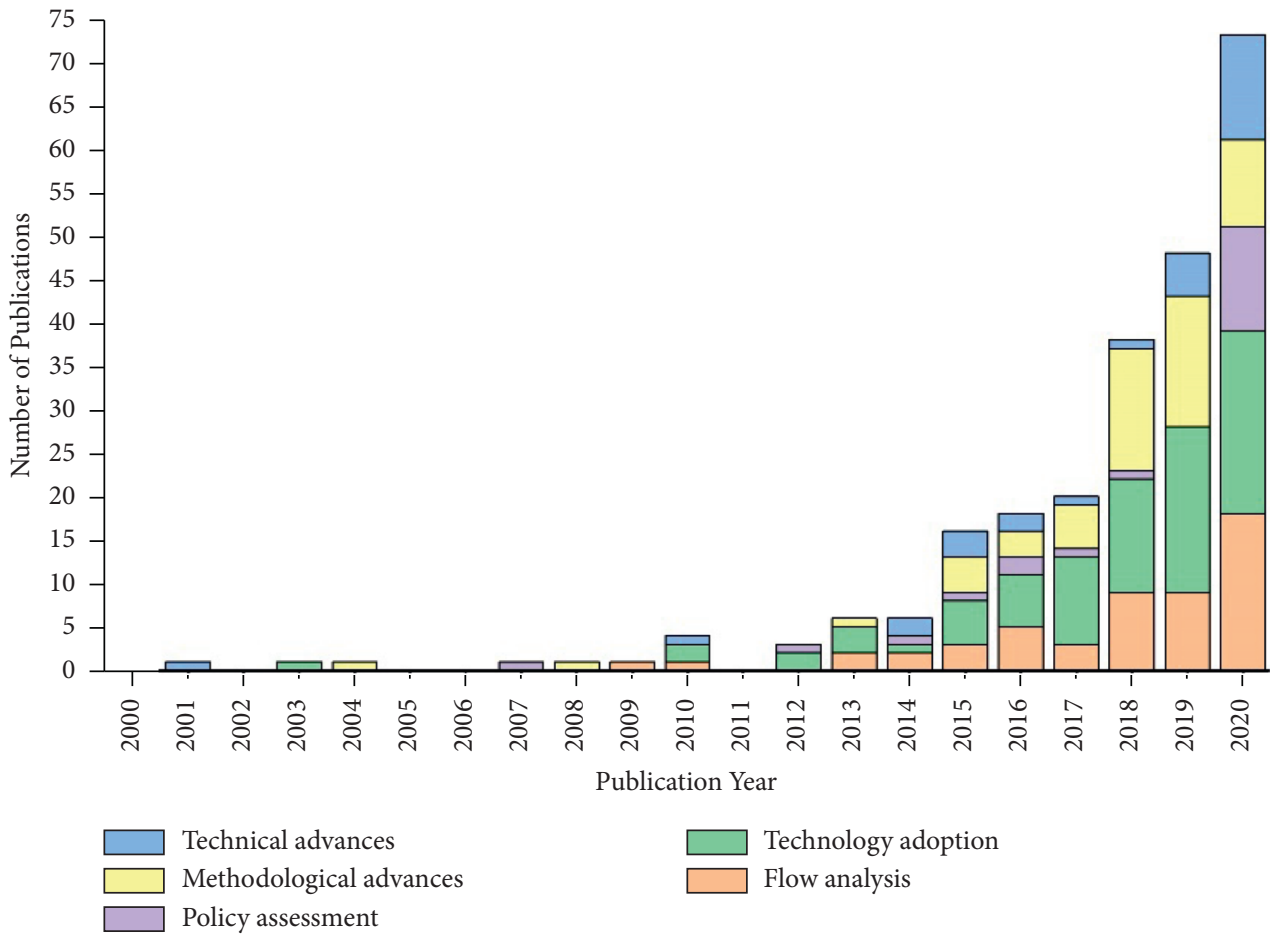

FIGURE 4: Aims of research for the study of mobile technology in transport behavior.

We also examined the transport mode recognition of the included articles. We deducted that public transport, walking, and cycling are currently focused on providing opportunities for increased accessibility before and after trips, with over two-thirds of the relevant studies published in 2019 and 2020, as shown in Figure 7. We attribute the high research interest to the proliferation of wearable sensors, location-based technology, and 


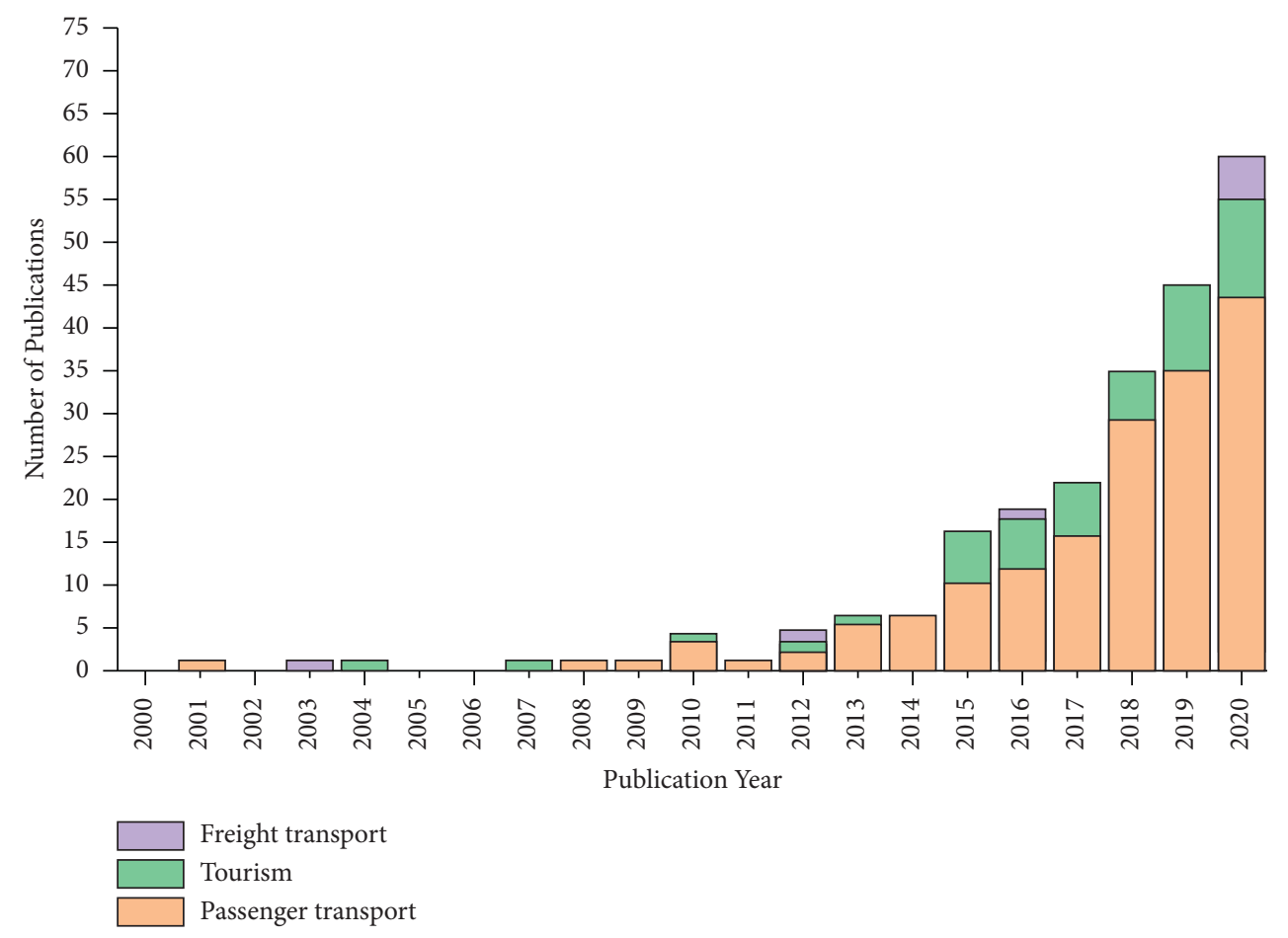

FIGURE 5: Investigated sectors for the study of mobile technology in transport behavior.

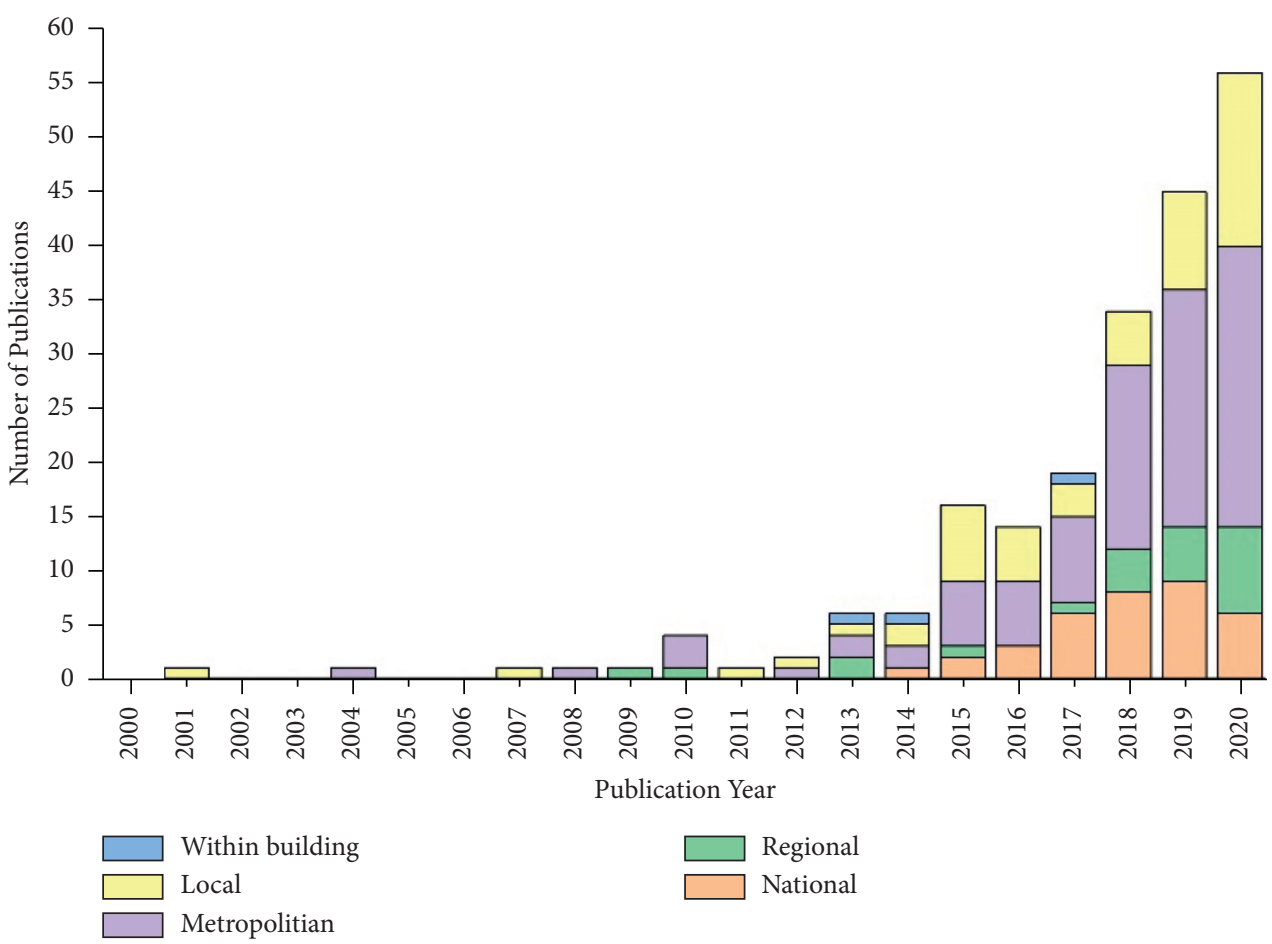

FIgURE 6: Spatial placements of activities for the study of mobile technology in transport behavior.

efficient algorithms. The trend and focus of research on walking and cycling modes revealed the scholarly attention given to accessibility issues in the public realm. With regard to the particular modes under which research on the topic was conducted, thirty-seven of the research papers (25\%) revolved around automobiles. In addition, nine papers on trains and three papers on air transport were included. 


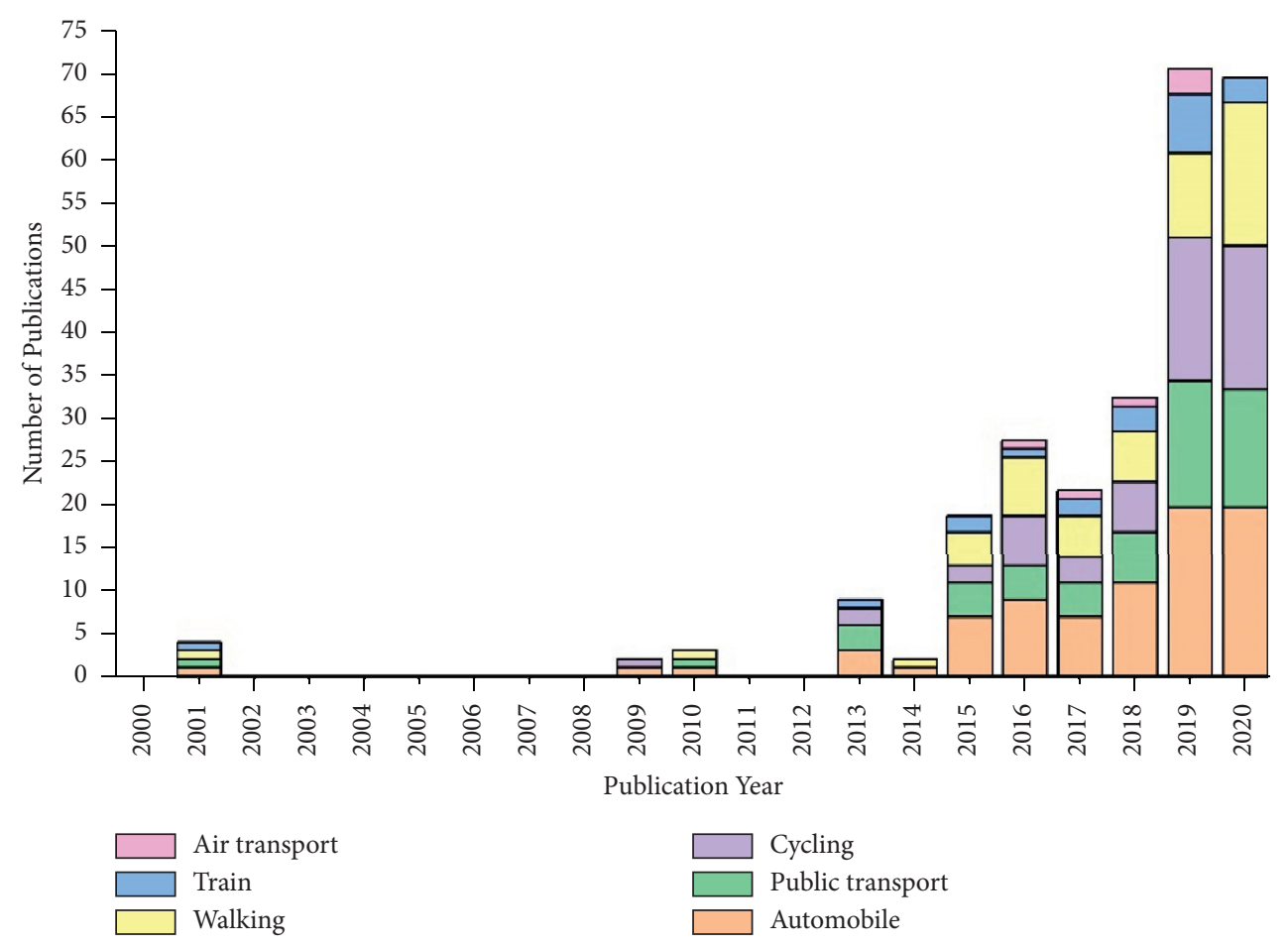

FIGURE 7: Investigated modes for the study of mobile technology in transport behavior.

We identified the core of pervasive mobile computing in transport behavior studies as the computational ability to facilitate effective communication via messages and thus making the acquisition of transport services and products more frequent on a mobile device. Table 3 presents a summary of the pervasive computing methods in the studies. Researchers have evaluated ways of interacting that enrich mobility. The literature analysis identified two major classifications in the forms of pervasive computing. The first collection of studies deployed real-time systems. These studies consistently show that the provision of timely and appropriate information on travel was key to the performance of transport systems in general and transport decision-making in particular.

The other stream of research on pervasive computing focused on behavioral outcomes of gamification mechanisms, including points, badges, and leaderboards. Points were found to be the most popular engagement method used to create a sensation of involvement and growth. Leaderboards allowed friendly competition between riders and meaningful conversations about a certain objective, usually being carbon footprint reduction, active travel miles, and energy savings. Badges let riders receive appreciation for their efforts and help them recognize the value of behavior changes. They have been increasingly used in smartphone app design and implementation.

3.4. Bibliometric Investigation. The bibliometric investigation included 236 articles. After visualizing these groups in Figure 8, we identified remarkable citation networks. Each of them is associated with an obvious research linkage. The links and their tone indicate that most networks in the interdisciplinary area of research are spearheading and significant. The central network published most of its articles in analytical models, which expanded to various subjects in the proximity of travel behavior and systems. There are also articles published on behavioral models and promotion, mainly with travel products. The other networks are smaller but more concentrated than the central network.

Figure 9 illustrates that many small networks of institutions have written most articles to explore the challenges of right technological use. The central networks comprised multiple renowned universities with a continuous effort on mobile phone data analytics. In the core of the network is, among others Massachusetts Institute of Technology who collaborated with research groups in North America, Europe, and Asia, conducting a wide variety of mobility studies. Recent networks exhibited strong collaborations in the broader areas of smartphone app developments.

Figure 10 presents the CiteSpace map of the most frequently occurring keywords and their respective co-occurrence links. The years on the $x$-axis correspond to the first time the keyword was mentioned as a declared keyword. The most frequent keywords are time, system, model, travel behavior, technology acceptance model, information, pattern, smartphone, usage, mode choice, and bicycle. Noticeably, apps and data types have not been selected. This means that studies focus on real-world problems encountered by the users and the transport system. As expected, bicycle and mode choice are the most recent keywords. They reflect that research interests have focused on improving the use of slow modes instead of the information system itself. Between 2010 and 2015, the relatively high frequency of the 
TABLE 3: Summary of pervasive computing methods and references.

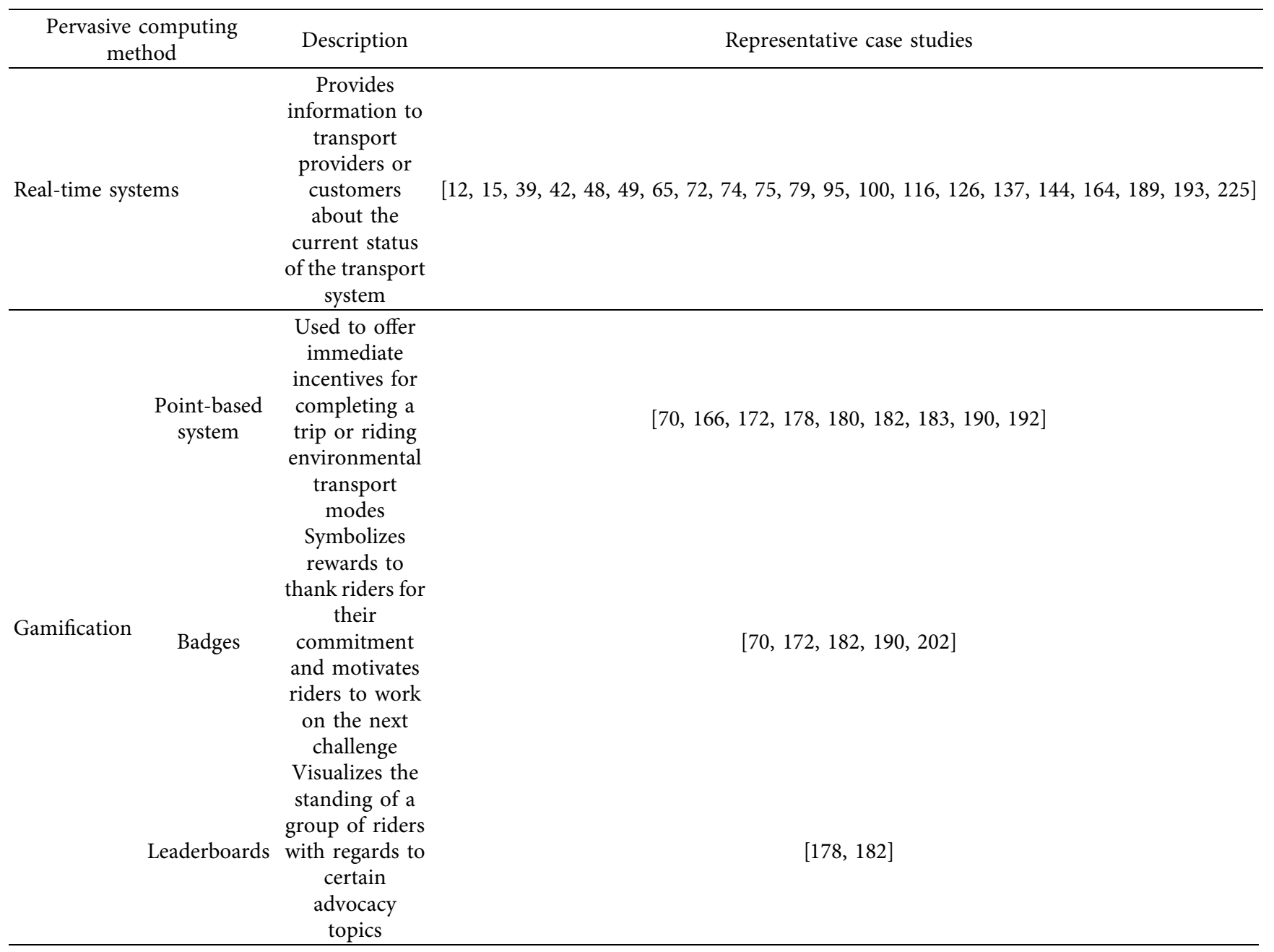

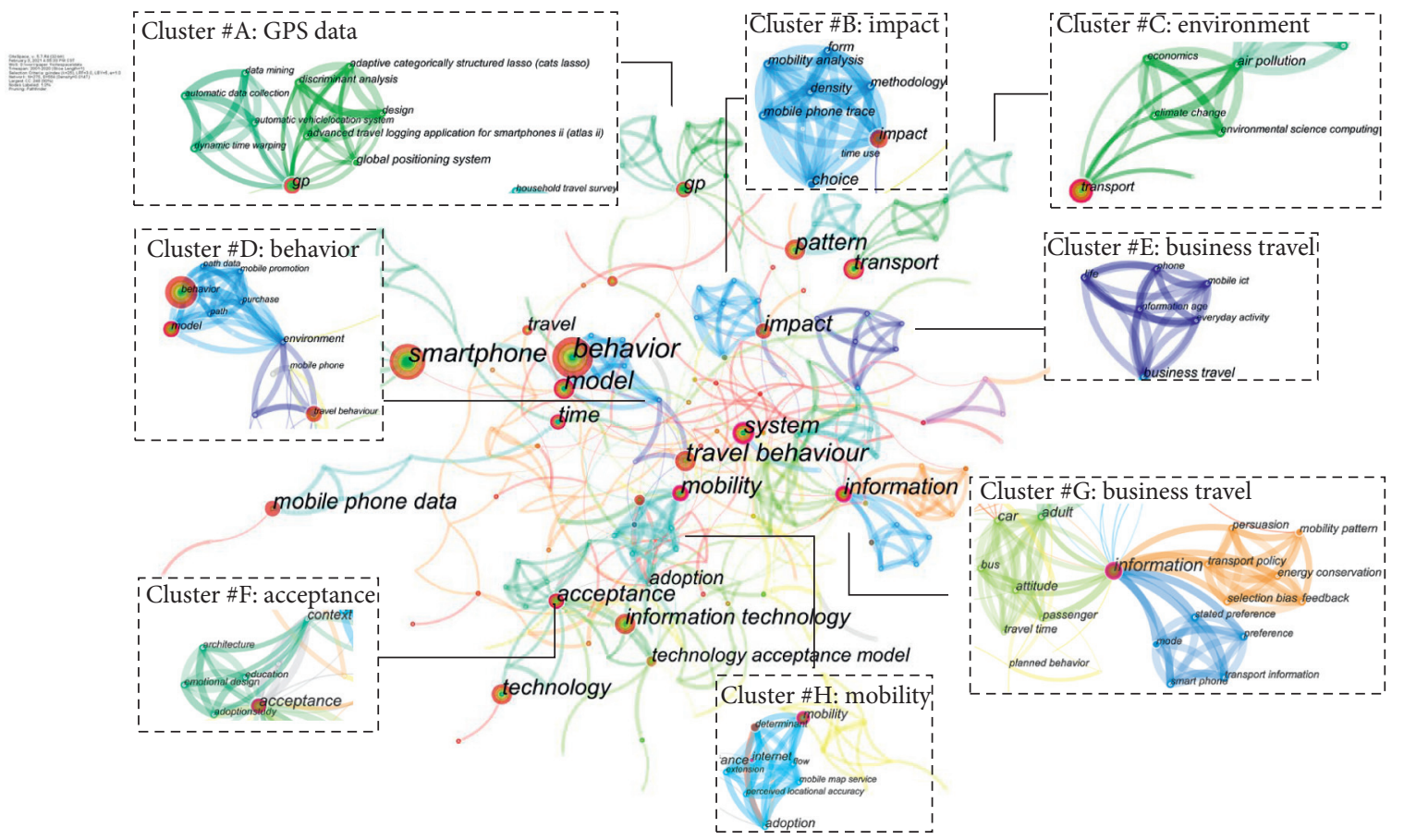

Figure 8: Cluster view of keyword concurrence of references during 2000-2020. 


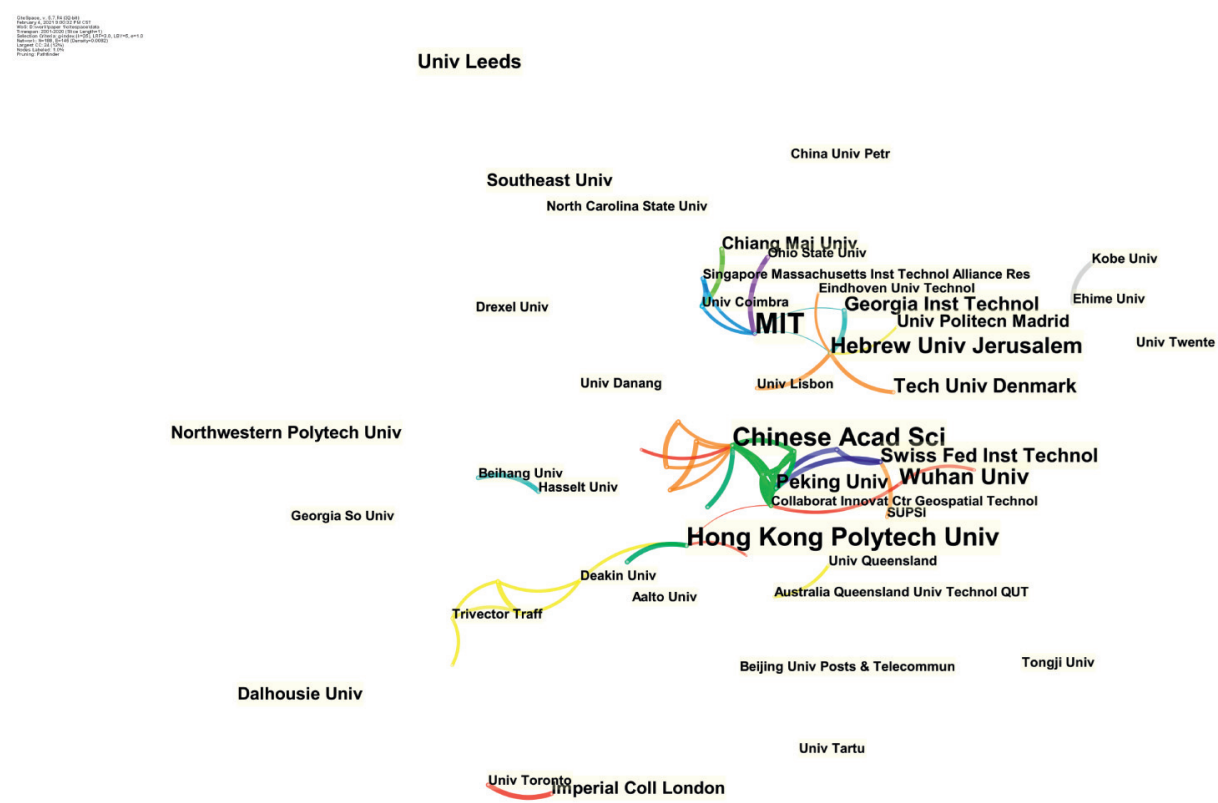

FIgURE 9: Cluster view of institutional collaboration network of references during 2000-2020.

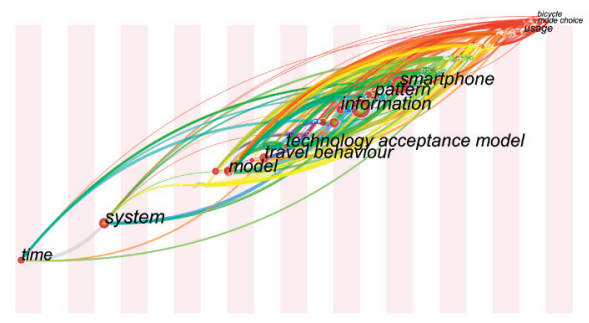

Figure 10: Temporal evolution of research keywords of references cited during 2000-2020.

words "technology acceptance model" and "information" indicates how information design and user adoption have been substantial. On one hand, the research on the time dimension is conducted from a systemic perspective, as "time" and "system" were keywords in 2000 and 2004, respectively.

3.5. Integrated Research Model. Even if previous studies have deployed mobile phones in transport behavior studies, the literature study revealed that no integrated research model had been drafted to summarize the intersection in these domains, including system design, data collection, transport analytics, and behavioral outcomes. By acknowledging the contributions already made in the existing literature, this study suggests an integrated research model, as shown in Figure 11, to reflect the research questions being asked, the underlying research logic, and the selection of research methods.

The literature analysis revealed that the two decades of progress consisted of research on topics in mobility (connection, accessibility, sustainability, safety, and health), interests in methodological advances (transport modeling, fine-grained mode detection, data collection methods, and analytics), and applications of well-established statistical techniques (structural equation models, logit models, and regression models). Our findings signify the growing utilization of a variety of mobile phone data before wide access to researchers, designers, and decision-makers.

Through the article-by-article examination of related work in this study, we found that transport app design has been supported with increasingly appealing features and contents. Studies have confirmed that mobile phone use leads to transport behavior changes through the mediation of riders' technology acceptance and adoption. Accordingly, the research model posits that design elements of smartphone apps influence riders' mobility, which in turn help make informed decisions in the geographical context. Drawing on the previous findings, the research model posits that riders' geographical and temporal placement of mobility still constructs all the orientation-destination relations; in the era of mobile phone use, it will stem from the interaction between (1) app-based design elements and (2) riders' technology acceptance and adoption and the transport behavioral outcomes. 


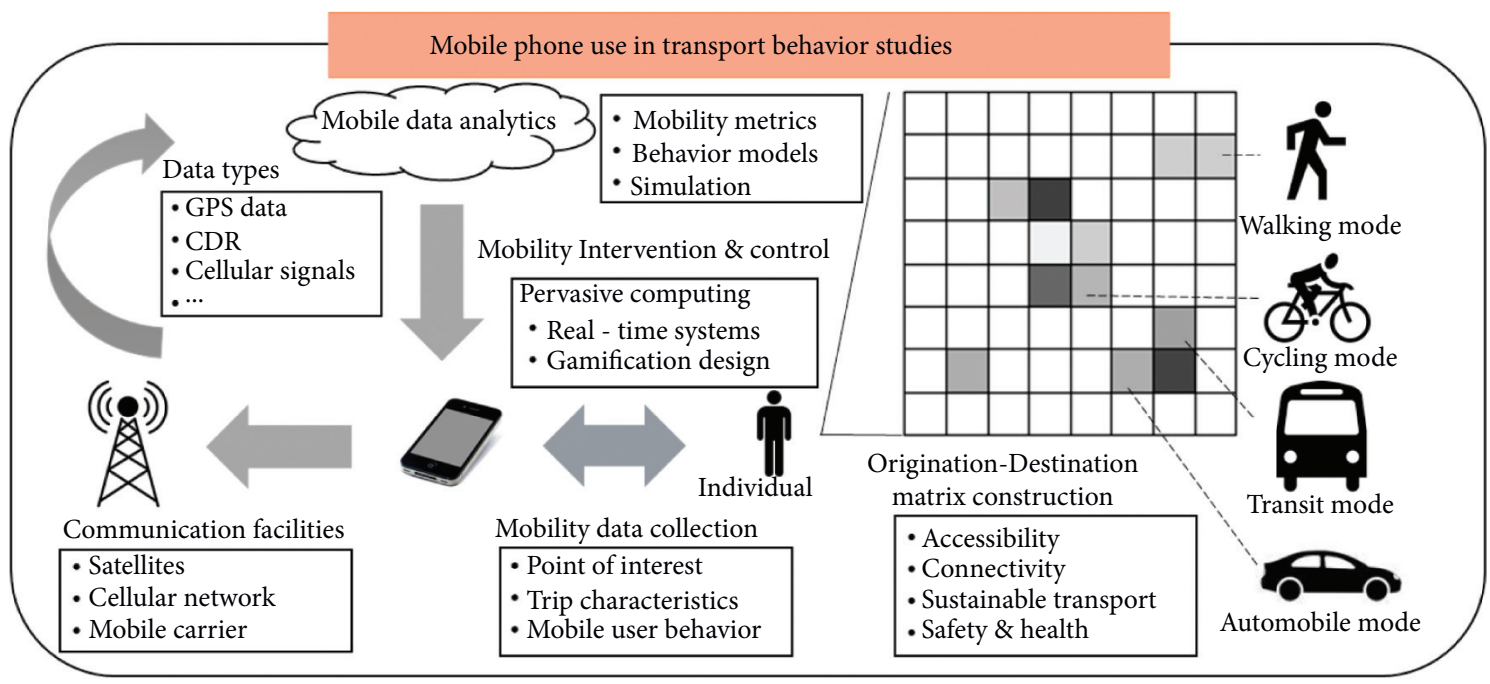

FIGURE 11: Integrated research model based on the synthesis of progress made in 2000-2020.

\section{Critical Discussion}

The literature review demonstrated that mobile technology in smartphone apps and data systems could be employed for transport behavior understanding, as summarized in $\mathrm{Ta}-$ ble 4 . Smartphone apps are appropriate for real-time information, whereas the movement of individuals is efficiently collected by cellular signals, CDRs, GPS/GNSS, and usage data. GPS/GNSS data are essential source for understanding all aspects of mobility provided that the assessment is increasingly conducted based on tracks, open data, and GIS tools. Transport systems are characterized by connection, accessibility, and rider-centered services, substantially benefiting from emerging paradigms in the digital age. In this process, using GPS data is still the most important step to supply highly accurate spatial-temporal data, recognizing the overall visibility and traceability from transport behavior understanding to the assessment of network performance.

Cellular signals are beneficial for mobility pattern analysis because the signals facilitate data collection at the disaggregated level. The advantage of signal data is the accuracy in estimating crow flow and density, a difficult task to achieve with traditional surveying methods [247]. Individual choices of transport routes and destinations are described by the preferences of service attributes. By collecting and analyzing data at the cellular positioning level, it is possible to obtain valuable origination-destination matrices [254]. With the help of geographical information, we can estimate travels and identify transport modes [255]. This insight is at another level of behavior understanding than other types of mobile data can deliver.

With regard to algorithms, cellular signals and CDRs data are appropriate to apply supervised learning, clustering, and transport mode detection, whereas GPS data could be organized by advanced programs of automatic variogram fitting and hot spot discovery. Clustering algorithms are chosen for the usage data and app evaluation due to their efficient segmentation of groups.
Regression models have been constructed to analyze mobile phone network data. Multinominal logit analysis is prevalent for investigating the choice outcomes of services and products, even influenced by digitalization. The strength of logit analysis attributes to the scalability of the model, as transport survey can be complemented by smartphone data that reveal more behavioral dynamics. Structural equation models address the relationships between multiple exogenous and endogenous, often unobserved, variables and are employed in observational research of usage data and app evaluation. In addition, it is a data-processing method for the GPS travel survey.

This section presents how the studies on mobile phone use in transport behavior studies can constitute a discussion on the mobility value of mobile phone data, pervasive usercentric design, forward-looking at freight transport, digital adoption, and the major impacts of mobile technology on transport systems.

4.1. Further Interpretation of Mobile Data Value from a Scientific Perspective. While employing mobile phone data is increasing, its contested value remains largely unexplored. Most of the existing literature emphasizes the process of combining data from multiple sources. However, previous studies have started capturing value from new data from an activity location inference perspective but in an extreme case of an epicenter [256]. Of particular importance is the ability to leverage these mobile data, but little understanding is acquired with regard to their mobility value from different perspectives. This point can be best studied by investigating the relationship of mobility, data, and construction of value, as Spinney and Lin discovered [257]. Stakeholders can now not only assess the causal effect but also interpret the hybridity of movements converted into data that have not been previously available. Based on the literature study, we argue that sourcing, management, and analysis of mobile phone data cannot merely be treated as one specific and delimited type to well-defined data science. Instead, the ways that 
TABLE 4: Mobile technology for transport behavior understanding.

\begin{tabular}{|c|c|c|c|c|c|}
\hline & Smartphone apps & Cellular signals & CDRs & GPS/GNSS data & Usage data \\
\hline $\begin{array}{l}\text { Technology } \\
\text { preparation }\end{array}$ & $\begin{array}{l}\text { A software that matches } \\
\text { riders with transport } \\
\text { service providers }\end{array}$ & $\begin{array}{l}\text { Mobile phone network data } \\
\text { collected by } \\
\text { telecommunication operators } \\
\text { for maintenance purposes }\end{array}$ & $\begin{array}{l}\text { Geolocation data } \\
\text { for each rider's } \\
\text { route }\end{array}$ & $\begin{array}{c}\text { Details about user's } \\
\text { arrival, visiting and time } \\
\text { spending with } \\
\text { technological features }\end{array}$ & \\
\hline $\begin{array}{l}\text { Available } \\
\text { algorithms }\end{array}$ & $\begin{array}{c}\text { Naïve bayes, clustering, } \\
\text { trace processing, route } \\
\text { planning }\end{array}$ & $\begin{array}{l}\text { Tower signal triangulation, } \\
\text { moving-or-staying } \\
\text { identification, supervised } \\
\text { learning, clustering, data } \\
\text { transfer, fuzzy logic }\end{array}$ & $\begin{array}{c}\text { Supervised } \\
\text { learning, } \\
\text { clustering, mode } \\
\text { detection, } \\
\text { behavior based }\end{array}$ & $\begin{array}{l}\text { Automatic variogram } \\
\text { fitting, prey-predator, } \\
\text { clustering, hot spot } \\
\text { discovery, learning, fuzzy } \\
\text { logic, map-matching, } \\
\text { recursive search, trip- } \\
\text { breaking, route planning, } \\
\text { critical point, gravity } \\
\text { estimation }\end{array}$ & $\begin{array}{l}\text { Parameter } \\
\text { estimation, } \\
\text { clustering, } \\
\text { recursive search, } \\
\text { search heuristic }\end{array}$ \\
\hline $\begin{array}{l}\text { Statistical } \\
\text { models }\end{array}$ & $\begin{array}{l}\text { Structural equation } \\
\text { models, model of the } \\
\text { theory of planned } \\
\text { behavior, discrete choice } \\
\text { models, logistic } \\
\text { regression, multilevel } \\
\text { regression }\end{array}$ & $\begin{array}{c}\text { Multiple liner regression, } \\
\text { bimodal }\end{array}$ & $\begin{array}{l}\text { Proc mixed, } \\
\text { logistic } \\
\text { regression, } \\
\text { general liner } \\
\text { model }\end{array}$ & $\begin{array}{l}\text { Regression tree, bayesian } \\
\text { multilevel regression, } \\
\text { linear regression, } \\
\text { structural equation } \\
\text { models, discrete choice } \\
\text { models }\end{array}$ & $\begin{array}{l}\text { Discrete choice } \\
\text { models }\end{array}$ \\
\hline $\begin{array}{l}\text { Application } \\
\text { area }\end{array}$ & All & $\begin{array}{l}\text { Route or mode selection, } \\
\text { general transport behavior or } \\
\text { experience }\end{array}$ & $\begin{array}{l}\text { Route or mode } \\
\text { selection }\end{array}$ & $\begin{array}{l}\text { Route or mode selection, } \\
\text { sustainable mobility, } \\
\text { smartphone usage, } \\
\text { health, general transport } \\
\text { behavior, or experience }\end{array}$ & $\begin{array}{l}\text { Route or mode } \\
\text { selection, } \\
\text { sustainable } \\
\text { mobility, } \\
\text { smartphone } \\
\text { usage }\end{array}$ \\
\hline
\end{tabular}

mobile phone data are spatially and temporally organized-but also integrated-constitute critical insights into mobility. Hence, given the importance of mobile phone data on the inquiry of gathering facts and evidence, we draft these central questions that need to be answered by researchers:

(i) What is the mobility value of the proximity of actors interested in mobile phone data and relevant products?

(ii) How would the integration and hybridity of mobile phone data relate to critical insights into transport behavior?

4.2. Pervasive User-Centric Design of Smartphone Apps. Design is a fertile field that focuses on attracting users and identifying user needs as a fundamental challenge to adoption [116]. Previous studies demonstrate the importance of the design phase taking into account expressed requirements [258]. In line with overtaking technological limitations, any information systems design should continue to realize a user-centric methodology for identifying opportunities from potential needs. The next step of research is expected to tackle issues of consistency, scalability, and recognizability around the visual communication of mobile information systems, a research problem that has not been fully addressed according to the literature.

Mobile-driven incentives and gamification elements are viable options for behavior stimuli. They can be associated with appealing features and contents. Most importantly, the application of gaming elements in a nongame context has been strengthened across domains over recent years. However, long-term behavioral outcomes as a consequence of pervasive computing's integration with riders' mobile life are not fully elucidated in the literature. The acquisition of information from ubiquitous media might point riders to the perception of being manipulated and therefore encounter negative experiences such as annoyance and loss of performance. Given the blur of the physical world and digitalization, a critical question is as follows:

(i) How will the design efficiency and effectiveness of smartphone apps be guaranteed?

4.3. Impact of Mobile Technology on Transport Systems. Mobile phone use is key to the temporal and spatial coordination of travel activities in networked societies. An increasing amount of mobile phone data drives quantitative studies on urban systems to explain the large variety of processes occurring with geographical constraints. Aguiléra et al. pointed out the difficulty of approaching the wealth and complexity of possible interactions between information and communication technology [238]. This was confirmed by examining the more recent literature. Most contributions of the work revolve around the representation of mobility and impact analysis. Experimental results show that it is possible for gathering route choice information on a large-scale road network based on route choice inference models for digital trace collection [27]. As Cats and Jenelius demonstrated, real-time information could facilitate the understanding of transport networks' vulnerability and disruptions [259]. The 
literature still lacks a coherent understanding of the dominant mechanism overarching the relationship between mobile phone use and mobility patterns in urban areas. In light of this, we posit the following research questions:

(i) What motivation will riders' major determinants of transport behavior provide for the usage of mobile phones?

(ii) How would riders adapt in transport systems after the long-term survival of a behavior change technique?

4.4. Freight Transport. A growing prevalence of mobile devices in delivery and logistics systems is observed and enabled. Our literature analysis discovered that previous studies did not emphasize simulation-based analytics supported by mobile data, which could be considered a promising future research topic. Despite a few qualitative studies in supply chains and logistics, mobile phone use is rarely mentioned in the quantitative analysis of goods movement and freight planning. Mobile data-driven models are promising for handling the inherent complexity of freighting through aggregation (using zoning systems and spatial clusters). It is worth encouraging supply chain trading partners to engage in the exchange of freight data but, more importantly, to reflect location intelligence. The following question needs to be addressed:

(i) How should freight zoning systems be reached in mobile data (considering aggregation into product groups based on distribution requirements)?

4.5. Adoption. Potential adoption is crucial to the relevance of carrying out research on a technical concept, in particularly given the history of failures at digitalization. With only a handful of publications addressing adoption, our analysis reveals the inadequacy of scholarly attention on this aspect to meet diverse requirements and realistic constraints of end users. Looking past the adoption of mobile technology outlines the barriers to adoption to be the external pressure and perceived benefits.

As technology permeates differently between organizations and cohorts, we argue that mobile phone use will be subject to cascades and a long-term interaction with transport systems. To this end, the research must consider it sufficiently beneficial for them to reflect the intentions, motivations, and behavioral factors; however, no holistic model addressing this incremental adoption is provided. Given the lack of research on adoption, we suggest that future research prioritize the overarching question on:

(i) What are the most important barriers and opportunities to mobile phone implementation and to making a translational impact?

\section{Conclusions}

This literature study offers an overview of current research, a critical discussion, and a research agenda for mobile technology in transport behavior studies. Through systematic analysis and a synthesis of works, a contribution to current research on smartphone apps and data systems is the summary of progress over the past two decades $t$. For researchers and developers, we recommend that further studies revolve around the interpretation of the value of mobile phone data from a brand-new scientific perspective focusing on pervasive user-centric design, impact on transport systems, application in freighting, and the adoption process. The research work on slow modes of transport and a diversified methodological viewpoint (the existing research is dominated by a few institutions) of the literature provide new insights for where to focus further efforts to continue exploring the revolutionary role mobile phone.

Mobile technology contributes to future adoption as a number of such issues have arisen. What is crucial to understand from a researcher's perspective is that currently, there are no well-established frameworks that illustrate how the move from the data gathered from riders to the application of mobile technology could ensue for the transport sector. We have also viewed the mobile phone's integration with transport systems as a positive scenario at scale rather than just the last mile of personalization. Standpoints of how mobile phones relate to mobility differ between stakeholders. Our analysis suggests an array of questions to be addressed in future research, stressing the importance of a cumulative approach. Addressing the current challenges of mobile phone conceptual development listed here would likely provide a solid ground for evaluating actual implementations in terms of its intended effects to solve the grand challenges in urban systems.

\section{Data Availability}

The data used to support the findings of this study are available from the corresponding author upon request.

\section{Conflicts of Interest}

The authors declare that they have no conflicts of interest.

\section{Acknowledgments}

This work was supported by the KTH-CSC funding (grant no. 201600160048) and the Shandong Provincial Natural Science Foundation of China (grant no. ZR2019BG006).

\section{References}

[1] I. Boas, "Environmental change and human mobility in the digital age," Geoforum, vol. 85, pp. 153-156, 2017.

[2] A. Bwambale, C. Choudhury, and S. Hess, "Modelling longdistance route choice using mobile phone call detail record data: a case study of Senegal," Transportmetrica: Transportation Science, vol. 15, no. 2, pp. 1543-1568, 2019.

[3] P. Galpern, A. Ladle, F. Alaniz Uribe, B. Sandalack, and P. Doyle-Baker, "Assessing urban connectivity using volunteered mobile phone GPS locations," Applied Geography, vol. 93, pp. 37-46, 2018.

[4] K. Chin, H. Huang, C. Horn, I. Kasanicky, and R. Weibel, "Inferring fine-grained transport modes from mobile phone 
cellular signaling data," Computers, Environment and Urban Systems, vol. 77, p. 101348, 2019.

[5] J. Feng, S. Huang, and C. Chen, "Modeling user interaction with app-based reward system: a graphical model approach integrated with max-margin learning," Transportation Research Part C: Emerging Technologies, vol. 120, p. 102814, 2020.

[6] C. K. H. Tony, S. H. Chen, and Y. W. Lee, "Investigating the adoption intention of gamification apps on mobile services," International Journal of Mobile Communications, vol. 18, no. 3, pp. 273-299, 2020.

[7] P. Dacinia Crina and B. Florina, "The use of smartphone for the search of touristic information: an application of the theory of planned behavior," Economic Computation \& Economic Cybernetics Studies \& Research, vol. 54, no. 1/2020, pp. 125-140, 2020.

[8] M. B. Rojas, E. Sadeghvaziri, and X. Jin, "Comprehensive review of travel behavior and mobility pattern studies that used mobile phone data," Transportation Research Record: Journal of the Transportation Research Board, vol. 2563, no. 1, pp. 71-79, 2016.

[9] L. Joseph, A. Neven, K. Martens, O. Kweka, G. Wets, and D. Janssens, "Measuring individuals' travel behaviour by use of a GPS-based smartphone application in Dar es Salaam, Tanzania," Journal of Transport Geography, vol. 88, p. 102477, 2020.

[10] Y. Asakura and E. Hato, "Behavioral monitoring of public transport users through a mobile communication system," Journal of Advanced Transportation, vol. 35, no. 3, pp. 289-304, 2001.

[11] C. Chen, "CiteSpace II: detecting and visualizing emerging trends and transient patterns in scientific literature," Journal of the American Society for Information Science and Technology, vol. 57, no. 3, pp. 359-377, 2006.

[12] K. E. Watkins, B. Ferris, A. Borning, G. S. Rutherford, and D. Layton, "Where is my bus? Impact of mobile real-time information on the perceived and actual wait time of transit riders," Transportation Research Part A: Policy and Practice, vol. 45, no. 8, pp. 839-848, 2011.

[13] A. Tsirimpa, "Modeling the impact of traffic information acquisition from mobile devices during the primary tour of the day," Journal of Intelligent Transportation Systems, vol. 19, no. 2, pp. 125-133, 2015.

[14] N. A. Khan, M. A. Habib, and S. Jamal, "Effects of smartphone application usage on mobility choices," Transportation Research Part A: Policy and Practice, vol. 132, pp. 932-947, 2020.

[15] H. Gan, Y. Zhao, and J. Wei, "Impact of smartphone-delivered real-time multi-modal information," International Journal of Mobile Communications, vol. 14, no. 3, p. 244, 2016.

[16] A. Faghih Imani, C. Harding, S. Srikukenthiran, E. J. Miller, and K. Nurul Habib, "Lessons from a large-scale experiment on the use of smartphone apps to collect travel diary data: the "city logger" for the greater golden horseshoe area," Transportation Research Record: Journal of the Transportation Research Board, vol. 2674, no. 7, pp. 299-311, 2020.

[17] G. Vich, O. Marquet, and C. Miralles-Guasch, "Suburban commuting and activity spaces: using smartphone tracking data to understand the spatial extent of travel behaviour," The Geographical Journal, vol. 183, no. 4, pp. 426-439, 2017.

[18] N. Caceres, L. M. Romero, and F. G. Benitez, "Exploring strengths and weaknesses of mobility inference from mobile phone data vs. travel surveys," Transportmetrica: Transportation Science, vol. 16, no. 3, pp. 574-601, 2020.

[19] S. Phithakkitnukoon, T. Sukhvibul, M. Demissie, Z. Smoreda, J. Natwichai, and C. Bento, "Inferring social influence in transport mode choice using mobile phone data," EPJ Data Science, vol. 6, no. 1, p. 11, 2017.

[20] A. Sevtsuk and C. Ratti, "Does urban mobility have a daily routine? Learning from the aggregate data of mobile networks," Journal of Urban Technology, vol. 17, no. 1, pp. 41-60, 2010.

[21] F. Calabrese, M. Diao, G. Di Lorenzo, J. Ferreira, and C. Ratti, "Understanding individual mobility patterns from urban sensing data: a mobile phone trace example," Transportation Research Part C: Emerging Technologies, vol. 26, pp. 301-313, 2013.

[22] N. E. Williams, T. A. Thomas, M. Dunbar, N. Eagle, and A. Dobra, "Measures of human mobility using mobile phone records enhanced with GIS data," PLoS One, vol. 10, no. 7, Article ID e0133630, 2015.

[23] S. Bernardi, L. La Paix-Puello, and K. Geurs, "Modelling route choice of Dutch cyclists using smartphone data," Journal of Transport and Land Use, vol. 11, no. 1, 2018.

[24] B. Toader, F. Sprumont, S. Faye, M. Popescu, and F. Viti, "Usage of smartphone data to derive an indicator for collaborative mobility between individuals," ISPRS International Journal of Geo-Information, vol. 6, no. 3, p. 62, 2017.

[25] Y. Lu, A. Misra, W. Sun, and H. Wu, "Smartphone sensing meets transport data: a collaborative framework for transportation service analytics," IEEE Transactions on Mobile Computing, vol. 17, no. 4, pp. 945-960, 2018.

[26] I. Semanjski, S. Gautama, R. Ahas, and F. Witlox, "Spatial context mining approach for transport mode recognition from mobile sensed big data," Computers, Environment and Urban Systems, vol. 66, pp. 38-52, 2017.

[27] P. Sakamanee, S. Phithakkitnukoon, Z. Smoreda, and C. Ratti, "Methods for inferring route choice of commuting trip from mobile phone network data," ISPRS International Journal of Geo-Information, vol. 9, no. 5, p. 306, 2020.

[28] R. Hu, Y. Liu, Y. Li, J. Zhou, S. Ma, and H. Xiong, "Exploiting user preference and mobile peer influence for human mobility annotation," ACM Transactions on Knowledge Discovery from Data, vol. 14, no. 6, pp. 1-18, 2020.

[29] S. Park, Y. Xu, L. Jiang, Z. Chen, and S. Huang, "Spatial structures of tourism destinations: a trajectory data mining approach leveraging mobile big data," Annals of Tourism Research, vol. 84, p. 102973, 2020.

[30] C. Harding, A. Faghih Imani, S. Srikukenthiran, E. J. Miller, and K. Nurul Habib, "Are we there yet? Assessing smartphone apps as full-fledged tools for activity-travel surveys," Transportation, vol. 48, no. 5, pp. 2433-2460, 2020.

[31] Y. Xu, X. Li, S.-L. Shaw, F. Lu, L. Yin, and B. Y. Chen, "Effects of data preprocessing methods on addressing location uncertainty in mobile signaling data," Annals of the Association of American Geographers, vol. 111, no. 2, pp. 515-539, 2021.

[32] S. Zhang, Y. Yang, F. Zhen, and T. Lobsang, "Exploring temporal activity patterns of urban areas using aggregated network-driven mobile phone data: a case study of Wuhu, China," Chinese Geographical Science, vol. 30, no. 4, pp. 695-709, 2020.

[33] J. K. Eom, K.-S. Lee, J. Y. Song, and J. Lee, "Analysis of mobile phone data to compare mobility flows and hotspots before and after the opening of high-speed railway: case study of honam KTX in Korea," Applied Sciences, vol. 10, no. 14, p. 5009, 2020. 
[34] L. Gong, M. Jin, Q. Liu, Y. Gong, and Y. Liu, "Identifying urban residents' activity space at multiple geographic scales using mobile phone data," ISPRS International Journal of Geo-Information, vol. 9, no. 4, p. 241, 2020.

[35] Y. Lu, F. Yuan, J. Lin, and K. Yuan, “TouristGo: a locationbased mobile game to improve tourist experience by visiting path optimisation," Personal and Ubiquitous Computing, vol. 24, no. 3, pp. 405-418, 2020.

[36] G. Zhong, T. Yin, J. Zhang, S. He, and B. Ran, "Characteristics analysis for travel behavior of transportation hub passengers using mobile phone data," Transportation, vol. 46, no. 5, pp. 1713-1736, 2019.

[37] F. Wang, J. Wang, J. Cao, C. Chen, and X. Ban, "Extracting trips from multi-sourced data for mobility pattern analysis: an app-based data example," Transportation Research Part C: Emerging Technologies, vol. 105, pp. 183-202, 2019.

[38] H. Wu, L. Liu, Y. Yu, Z. Peng, H. Jiao, and Q. Niu, “An agentbased model simulation of human mobility based on mobile phone data: how commuting relates to congestion," ISPRS International Journal of Geo-Information, vol. 8, no. 7, p. 313, 2019.

[39] C.-C. Chen and J.-L. Tsai, "Determinants of behavioral intention to use the personalized location-based mobile tourism application: an empirical study by integrating TAM with ISSM," Future Generation Computer Systems, vol. 96, pp. 628-638, 2019.

[40] C.-M. Chuang, "A current travel model: smart tour on mobile guide application services," Current Issues in Tourism, vol. 23, no. 18, pp. 2333-2352, 2020.

[41] Z. Ghaderi, P. Hatamifar, and L. Ghahramani, "How smartphones enhance local tourism experiences?" Asia Pacific Journal of Tourism Research, vol. 24, no. 8, pp. 778-788, 2019.

[42] M. Danaf, B. Atasoy, C. L. de Azevedo et al., "Context-aware stated preferences with smartphone-based travel surveys," Journal of Choice Modelling, vol. 31, pp. 35-50, 2019.

[43] E.-h. Yoo, "How short is long enough? Modeling temporal aspects of human mobility behavior using mobile phone data," Annals of the Association of American Geographers, vol. 109, no. 5, pp. 1415-1432, 2019.

[44] Z. Zhao, S.-L. Shaw, L. Yin et al., "The effect of temporal sampling intervals on typical human mobility indicators obtained from mobile phone location data," International Journal of Geographical Information Science, vol. 33, no. 7, pp. 1471-1495, 2019.

[45] A. Bwambale, C. F. Choudhury, and S. Hess, "Modelling trip generation using mobile phone data: a latent demographics approach," Journal of Transport Geography, vol. 76, pp. 276-286, 2019.

[46] T. Thomas, L. La Paix Puello, and K. Geurs, "Intrapersonal mode choice variation: evidence from a four-week smartphone-based travel survey in The Netherlands," Journal of Transport Geography, vol. 76, pp. 287-300, 2019.

[47] D. Bachir, G. Khodabandelou, V. Gauthier, M. El Yacoubi, and J. Puchinger, "Inferring dynamic origin-destination flows by transport mode using mobile phone data," Transportation Research Part C: Emerging Technologies, vol. 101, pp. 254-275, 2019.

[48] W. Ma and X. Chen, "Bus frequency optimization considering user behaviour based on mobile bus applications," IET Intelligent Transport Systems, vol. 13, no. 4, p. 11, 2018.

[49] U. Berggren, C. Johnsson, H. Svensson, and A. Wretstrand, "Exploring waiting times in public transport through a semi- automated dedicated smartphone app survey," Travel Behaviour and Society, vol. 15, pp. 1-14, 2019.

[50] T. Joewono, A. Tarigan, and M. Rizki, "Segmentation, classification, and determinants of in-store shopping activity and travel behaviour in the digitalisation era: the context of a developing country," Sustainability, vol. 11, no. 6, p. 1591, 2019.

[51] A. Masso, S. Silm, and R. Ahas, "Generational differences in spatial mobility: a study with mobile phone data," Population, Space and Place, vol. 25, no. 2, Article ID e2210, 2019.

[52] B.-h. Nahmias-Biran, Y. Han, S. Bekhor, F. Zhao, C. Zegras, and M. Ben-Akiva, "Enriching activity-based models using smartphone-based travel surveys," Transportation Research Record: Journal of the Transportation Research Board, vol. 2672, no. 42, pp. 280-291, 2018.

[53] X. Zhao, X. Lu, Y. Liu, J. Lin, and J. An, “Tourist movement patterns understanding from the perspective of travel party size using mobile tracking data: a case study of Xi'an, China," Tourism Management, vol. 69, pp. 368-383, 2018.

[54] H. T. Marques-Neto, F. H. Z. Xavier, W. Z. Xavier et al., "Understanding human mobility and workload dynamics due to different large-scale events using mobile phone data," Journal of Network and Systems Management, vol. 26, no. 4, pp. 1079-1100, 2018.

[55] J. Feng, Y. Li, F. Xu, and D. Jin, "A bimodal model to estimate dynamic metropolitan population by mobile phone data," Sensors, vol. 18, no. 10, p. 3431, 2018.

[56] H. Q. Vu, G. Li, R. Law, and Y. Zhang, "Tourist activity analysis by leveraging mobile social media data," Journal of Travel Research, vol. 57, no. 7, pp. 883-898, 2018.

[57] M. Batran, M. Mejia, H. Kanasugi, Y. Sekimoto, and R. Shibasaki, "Inferencing human spatiotemporal mobility in greater maputo via mobile phone big data mining," ISPRS International Journal of Geo-Information, vol. 7, no. 7, p. 259, 2018.

[58] X. Zhou, A. G. Yeh, W. Li, and Y. Yue, "A commuting spectrum analysis of the jobs-housing balance and selfcontainment of employment with mobile phone location big data," Environment and Planning B: Urban Analytics and City Science, vol. 45, no. 3, pp. 434-451, 2018.

[59] Y. Wang, G. H. D. A. Correia, B. van Arem, and H. J. P. Timmermans, “Understanding travellers' preferences for different types of trip destination based on mobile internet usage data," Transportation Research Part C: Emerging Technologies, vol. 90, pp. 247-259, 2018.

[60] P. J. Zufiria, D. Pastor-Escuredo, L. Úbeda-Medina et al., "Identifying seasonal mobility profiles from anonymized and aggregated mobile phone data: application in food security," PLoS One, vol. 13, no. 4, Article ID e0195714, 2018.

[61] Z. Liu, T. Ma, Y. Du, T. Pei, J. Yi, and H. Peng, "Mapping hourly dynamics of urban population using trajectories reconstructed from mobile phone records," Transactions in GIS, vol. 22, no. 2, pp. 494-513, 2018.

[62] H. Du, Z. Yu, F. Yi, Z. Wang, Q. Han, and B. Guo, "Recognition of group mobility level and group structure with mobile devices," IEEE Transactions on Mobile Computing, vol. 17, no. 4, pp. 884-897, 2018.

[63] F. Wang and C. Chen, "On data processing required to derive mobility patterns from passively-generated mobile phone data," Transportation Research Part C: Emerging Technologies, vol. 87, pp. 58-74, 2018.

[64] H. J. Yun, D. J. Kang, and M. J. Lee, "Spatiotemporal distribution of urban walking tourists by season using GPS- 
based smartphone application," Asia Pacific Journal of Tourism Research, vol. 23, no. 11, pp. 1047-1061, 2018.

[65] Y.-J. Chang, G. Paruthi, H.-Y. Wu, H.-Y. Lin, and M. W. Newman, "An investigation of using mobile and situated crowdsourcing to collect annotated travel activity data in real-word settings," International Journal of HumanComputer Studies, vol. 102, pp. 81-102, 2017.

[66] Y. Qiao, Y. Cheng, J. Yang, J. Liu, and N. Kato, "A mobility analytical framework for big mobile data in densely populated area," IEEE Transactions on Vehicular Technology, vol. 66, no. 2, pp. 1443-1455, 2017.

[67] G. W.-H. Tan, V. H. Lee, B. Lin, and K.-B. Ooi, "Mobile applications in tourism: the future of the tourism industry?" Industrial Management \& Data Systems, vol. 117, no. 3, pp. 560-581, 2017.

[68] P. Kamenjuk, A. Aasa, and J. Sellin, "Mapping changes of residence with passive mobile positioning data: the case of Estonia," International Journal of Geographical Information Science, vol. 31, no. 7, pp. 1425-1447, 2017.

[69] X. Yang, Z. Fang, Y. Xu et al., "Understanding spatiotemporal patterns of human convergence and divergence using mobile phone location data," ISPRS International Journal of Geo-Information, vol. 5, no. 10, p. 177, 2016.

[70] I. Semanjski, A. Lopez Aguirre, J. De Mol, and S. Gautama, "Policy 2.0 platform for mobile sensing and incentivized targeted shifts in mobility behavior," Sensors, vol. 16, no. 7, p. $1035,2016$.

[71] B. Assemi, H. Safi, M. Mesbah, and L. Ferreira, "Developing and validating a statistical model for travel mode identification on smartphones," IEEE Transactions on Intelligent Transportation Systems, vol. 17, no. 7, pp. 1920-1931, 2016.

[72] X. Zhou, W. Yu, and W. C. Sullivan, "Making pervasive sensing possible: effective travel mode sensing based on smartphones," Computers, Environment and Urban Systems, vol. 58, pp. 52-59, 2016.

[73] B. Guo, Y. Liang, Z. Yu, M. Li, and X. Zhou, "From mobile phone sensing to human geo-social behavior understanding: mobile phone sensing to human geo-social behavior," Computational Intelligence, vol. 32, no. 2, pp. 240-258, 2016.

[74] K. Papangelis, J. D. Nelson, S. Sripada, and M. Beecroft, "The effects of mobile real-time information on rural passengers," Transportation Planning and Technology, vol. 39, no. 1, pp. 97-114, 2016.

[75] Z. Patterson and K. Fitzsimmons, "DataMobile: smartphone travel survey experiment," Transportation Research Record: Journal of the Transportation Research Board, vol. 2594, no. 1, pp. 35-43, 2016.

[76] A. Carrel, P. S. C. Lau, R. G. Mishalani, R. Sengupta, and J. L. Walker, "Quantifying transit travel experiences from the users' perspective with high-resolution smartphone and vehicle location data: methodologies, validation, and example analyses," Transportation Research Part C: Emerging Technologies, vol. 58, pp. 224-239, 2015.

[77] Y. Xu, S.-L. Shaw, Z. Zhao, L. Yin, Z. Fang, and Q. Li, "Understanding aggregate human mobility patterns using passive mobile phone location data: a home-based approach," Transportation, vol. 42, no. 4, pp. 625-646, 2015.

[78] T. M. T. Do, O. Dousse, M. Miettinen, and D. Gatica-Perez, "A probabilistic kernel method for human mobility prediction with smartphones," Pervasive and Mobile Computing, vol. 20, pp. 13-28, 2015.

[79] H. Gan, "To switch travel mode or not? Impact of Smartphone delivered high-quality multimodal information," IET Intelligent Transport Systems, vol. 9, no. 4, pp. 382-390, 2015.
[80] P. Kourouthanassis, C. Boletsis, C. Bardaki, and D. Chasanidou, "Tourists responses to mobile augmented reality travel guides: the role of emotions on adoption behavior," Pervasive and Mobile Computing, vol. 18, pp. 71-87, 2015.

[81] S. Phithakkitnukoon, T. Horanont, A. Witayangkurn, R. Siri, Y. Sekimoto, and R. Shibasaki, "Understanding tourist behavior using large-scale mobile sensing approach: a case study of mobile phone users in Japan," Pervasive and Mobile Computing, vol. 18, pp. 18-39, 2015.

[82] A. Fonzone, "What do you do with your app?: study of bus rider decision making with real-time passenger information," Transportation Research Record: Journal of the Transportation Research Board, vol. 2535, no. 1, pp. 15-24, 2015.

[83] F. Zhao, F. C. Pereira, R. Ball et al., "Exploratory analysis of a smartphone-based travel survey in Singapore," Transportation Research Record: Journal of the Transportation Research Board, vol. 2494, no. 1, pp. 45-56, 2015.

[84] C. Chen, L. Bian, and J. Ma, "From traces to trajectories: how well can we guess activity locations from mobile phone traces?" Transportation Research Part C: Emerging Technologies, vol. 46, pp. 326-337, 2014.

[85] K. S. Kung, K. Greco, S. Sobolevsky, and C. Ratti, "Exploring universal patterns in human home-work commuting from mobile phone data," PLoS One, vol. 9, no. 6, Article ID e96180, 2014.

[86] M. B. Kjærgaard and H. Blunck, "Tool support for detection and analysis of following and leadership behavior of pedestrians from mobile sensing data," Pervasive and Mobile Computing, vol. 10, pp. 104-117, 2014.

[87] S. K. Hui, J. J. Inman, Y. Huang, and J. Suher, “The effect of in-store travel distance on unplanned spending: applications to mobile promotion strategies," Journal of Marketing, vol. 77, no. 2, pp. 1-16, 2013.

[88] Y. Yuan, M. Raubal, and Y. Liu, "Correlating mobile phone usage and travel behavior-a case study of Harbin, China," Computers, Environment and Urban Systems, vol. 36, no. 2, pp. 118-130, 2012.

[89] P. A. Gonzalez, J. S. Weinstein, S. J. Barbeau et al., "Automating mode detection for travel behaviour analysis by using global positioning systems-enabled mobile phones and neural networks," IET Intelligent Transport Systems, vol. 4, no. 1 , p. 37, 2010.

[90] C. Nobis and B. Lenz, "Communication and mobility behaviour-a trend and panel analysis of the correlation between mobile phone use and mobility," Journal of Transport Geography, vol. 17, no. 2, pp. 93-103, 2009.

[91] Y. Asakura and T. Iryo, "Analysis of tourist behaviour based on the tracking data collected using a mobile communication instrument," Transportation Research Part A: Policy and Practice, vol. 41, no. 7, pp. 684-690, 2007.

[92] Y. Asakura and E. Hato, "Tracking survey for individual travel behaviour using mobile communication instruments," Transportation Research Part C: Emerging Technologies, vol. 12, no. 3-4, pp. 273-291, 2004.

[93] T. E. Julsrud and J. M. Denstadli, "Smartphones, travel timeuse, and attitudes to public transport services. Insights from an explorative study of urban dwellers in two Norwegian cities," International Journal of Sustainable Transportation, vol. 11, no. 8, pp. 602-610, 2017.

[94] F. Alemi, G. Circella, S. Handy, and P. Mokhtarian, "What influences travelers to use Uber? Exploring the factors affecting the adoption of on-demand ride services in 
California," Travel Behaviour and Society, vol. 13, pp. 88-104, 2018.

[95] B. Ferris, K. Watkins, and A. Borning, "Location-aware tools for improving public transit usability," IEEE Pervasive Computing, vol. 9, no. 1, pp. 13-19, 2010.

[96] D. Wang, S. Park, and D. R. Fesenmaier, "The role of smartphones in mediating the touristic experience," Journal of Travel Research, vol. 51, no. 4, pp. 371-387, 2012.

[97] Y.-Y. Tseng, J. Knockaert, and E. T. Verhoef, "A revealedpreference study of behavioural impacts of real-time traffic information," Transportation Research Part C: Emerging Technologies, vol. 30, pp. 196-209, 2013.

[98] J. Yang, J. Dong, Z. Lin, and L. Hu, "Predicting market potential and environmental benefits of deploying electric taxis in Nanjing, China," Transportation Research Part D: Transport and Environment, vol. 49, pp. 68-81, 2016.

[99] S. Okazaki, S. Campo, L. Andreu, and J. Romero, "A latent class Analysis of Spanish travelers' mobile internet usage in travel planning and execution," Cornell Hospitality Quarterly, vol. 56, no. 2, pp. 191-201, 2015.

[100] A. Steinfeld, L. Bloomfield, S. Amick et al., "Increasing access to transit: localized mobile information," Journal of Urban Technology, vol. 26, no. 3, pp. 45-64, 2019.

[101] D. Ettema, J. Knockaert, and E. Verhoef, "Using incentives as traffic management tool: empirical results of the "peak avoidance" experiment," Transportation Letters, vol. 2, no. 1, pp. 39-51, 2010.

[102] J. Reif and D. Schmücker, "Exploring new ways of visitor tracking using big data sources: opportunities and limits of passive mobile data for tourism," Journal of Destination Marketing \& Management, vol. 18, p. 100481, 2020.

[103] C. Santamaria, F. Sermi, S. Spyratos et al., "Measuring the impact of COVID-19 confinement measures on human mobility using mobile positioning data. A European regional analysis," Safety Science, vol. 132, p. 104925, 2020.

[104] C. Li, J. Hu, Z. Dai, Z. Fan, and Z. Wu, "Understanding individual mobility pattern and portrait depiction based on mobile phone data," ISPRS International Journal of GeoInformation, vol. 9, no. 11, p. 666, 2020.

[105] F. Liu, D. Janssens, J. Cui, Y. Wang, G. Wets, and M. Cools, "Building a validation measure for activity-based transportation models based on mobile phone data," Expert Systems with Applications, vol. 41, no. 14, pp. 6174-6189, 2014.

[106] L. Rayle, S. Shaheen, N. Chan, D. Dai, and R. Cervero, “Appbased, on-demand ride services: comparing taxi and ridesourcing trips and user characteristics in san francisco," in Proceedings of the Transportation Research Board 94th Annual MeetingTransportation Research Board, Washington, DC, USA, December 2015.

[107] A. Komanduri, Z. Wafa, K. Proussaloglou, and S. Jacobs, "Assessing the impact of app-based ride share systems in an urban context: findings from Austin," Transportation Research Record: Journal of the Transportation Research Board, vol. 2672, no. 7, pp. 34-46, 2018.

[108] J. Gadziński, "Perspectives of the use of smartphones in travel behaviour studies: findings from a literature review and a pilot study," Transportation Research Part C: Emerging Technologies, vol. 88, pp. 74-86, 2018.

[109] J. Lynch, J. Dumont, E. Greene, and J. Ehrlich, "Use of a smartphone GPS application for recurrent travel behavior data collection," Transportation Research Record: Journal of the Transportation Research Board, vol. 2673, no. 7, pp. 89-98, 2019.
[110] E. Park and J. Ohm, "Factors influencing users' employment of mobile map services," Telematics and Informatics, vol. 31, no. 2, pp. 253-265, 2014.

[111] M. Engin, N. Kasap, and B. T. Sivrikaya, "User acceptance of shuttle bus decision support system based on smartphone probes," SAGE Open, vol. 10, no. 2, Article ID 215824402091952, 2020.

[112] N. Mallat, M. Rossi, V. K. Tuunainen, and A. Öörni, “An empirical investigation of mobile ticketing service adoption in public transportation," Personal and Ubiquitous Computing, vol. 12, no. 1, pp. 57-65, 2007.

[113] M. Vallespín, S. Molinillo, and F. Muñoz-Leiva, "Segmentation and explanation of smartphone use for travel planning based on socio-demographic and behavioral variables," Industrial Management \& Data Systems, vol. 117, no. 3, pp. 605-619, 2017.

[114] N. Louveton, R. McCall, V. Koenig, T. Avanesov, and T. Engel, "Driving while using a smartphone-based mobility application: evaluating the impact of three multi-choice user interfaces on visual-manual distraction," Applied Ergonomics, vol. 54, pp. 196-204, 2016.

[115] C. D. Cottrill, F. C. Pereira, F. Zhao et al., "Future mobility survey: experience in developing a smartphone-based travel survey in Singapore," Transportation Research Record: Journal of the Transportation Research Board, vol. 2354, no. 1, pp. 59-67, 2013.

[116] J. E. Dickinson, T. Cherrett, J. F. Hibbert et al., "Fundamental challenges in designing a collaborative travel app," Transport Policy, vol. 44, pp. 28-36, 2015.

[117] W.-K. Tan and Y.-C. Chen, “Tourists' work-related smartphone use at the tourist destination: making an otherwise impossible trip possible," Current Issues in Tourism, vol. 24, no. 11, pp. 1526-1541, 2021.

[118] K. Büchel and M. v. Ehrlich, "Cities and the structure of social interactions: evidence from mobile phone data," Journal of Urban Economics, vol. 119, p. 103276, 2020.

[119] Y. He and C. Csiszár, "Concept of mobile application for mobility as a service based on autonomous vehicles," Sustainability, vol. 12, no. 17, p. 6737, 2020.

[120] Y. Zhang, Y. Huang, Y. Wang, and T. W. Casey, "Who uses a mobile phone while driving for food delivery? The role of personality, risk perception, and driving self-efficacy," Journal of Safety Research, vol. 73, pp. 69-80, 2020.

[121] S. H. Hsieh and C. T. Lee, "Traces of mobility: examining location disclosure on social networks with mobile location tagging," Telematics and Informatics, vol. 49, p. 101366, 2020.

[122] D. Belanche, M. Flavián, and A. Pérez-Rueda, "Mobile apps use and WOM in the food delivery sector: the role of planned behavior, perceived security and customer lifestyle compatibility," Sustainability, vol. 12, no. 10, p. 4275, 2020.

[123] R. J. Nathan, V. Victor, M. Tan, and M. Fekete-Farkas, "Tourists' use of Airbnb app for visiting a historical city," Information Technology \& Tourism, vol. 22, no. 2, pp. 217242, 2020.

[124] C. Ahlström, J. Wachtmeister, M. Nyman, A. Nordenström, and K. Kircher, "Using smartphone logging to gain insight about phone use in traffic," Cognition, Technology \& Work, vol. 22, no. 1, pp. 181-191, 2020.

[125] J. Fardous, J. T. Du, P. Hansen, K.-K. R. Choo, and S. Huang, "Group trip planning and information seeking behaviours by mobile social media users: a study of tourists in Australia, Bangladesh and China," Journal of Information Science, vol. 47, no. 3, pp. 323-339, 2021. 
[126] C. Calvignac and J. Smolinski, "How can the use of a mobile application change the course of a sightseeing tour? A question of pace, gaze and information processing," Tourist Studies, vol. 20, no. 1, pp. 49-74, 2020.

[127] R. Etminani-Ghasrodashti and S. Hamidi, "Individuals' demand for ride-hailing services: investigating the combined effects of attitudinal factors, land use, and travel attributes on demand for app-based taxis in Tehran, Iran," Sustainability, vol. 11, no. 20, p. 5755, 2019.

[128] A. Douglas, "Mobile business travel application usage: are South African men really from Mars and women from Venus?" Journal of Hospitality and Tourism Technology, vol. 10, no. 3, pp. 269-285, 2019.

[129] J. W. C. Wong, I. K. W. Lai, and Z. Tao, "Sharing memorable tourism experiences on mobile social media and how it influences further travel decisions," Current Issues in Tourism, vol. 23, no. 14, pp. 1773-1787, 2020.

[130] C. C. Chen and S. S. Tsang, "Predicting adoption of mobile payments from the perspective of taxi drivers," IET Intelligent Transport Systems, vol. 13, no. 7, pp. 1116-1124, 2019.

[131] L. Lalicic and A. Dickinger, "An assessment of user-driven innovativeness in a mobile computing travel platform," Technological Forecasting and Social Change, vol. 144, pp. 233-241, 2019.

[132] W. Wang, "The influence of perceived technological congruence of smartphone application and air travel experience on consumers' attitudes toward price change and adoption," Journal of Hospitality and Tourism Technology, vol. 10, no. 2, pp. 122-135, 2019.

[133] R. I. Sarker, S. Kaplan, M. K. Anderson, S. Haustein, M. Mailer, and H. J. P. Timmermans, "Obtaining transit information from users of a collaborative transit app: platform-based and individual-related motivators," Transportation Research Part C: Emerging Technologies, vol. 102, pp. 173-188, 2019.

[134] S. Jamal and M. A. Habib, "Investigation of the use of smartphone applications for trip planning and travel outcomes," Transportation Planning and Technology, vol. 42, no. 3, pp. 227-243, 2019.

[135] H. Linton and R. J. Kwortnik, "Mobile usage in travel: bridging the supplier-user gap," International Journal of Contemporary Hospitality Management, vol. 31, no. 2, pp. 771-789, 2019.

[136] J. Zhang, T. Wu, and Z. Fan, "Research on precision marketing model of tourism industry based on user's mobile behavior trajectory," Mobile Information Systems, vol. 2019, Article ID 6560848, 14 pages, 2019.

[137] G. Velazquez, S. Kaplan, and A. Monzon, "Ex-ante and expost evaluation of a new transit information app: modeling use intentions and actual use," Transportation Research Record: Journal of the Transportation Research Board, vol. 2672, no. 50, pp. 56-65, 2018.

[138] T. McWilliams, N. Ward, B. Mehler, and B. Reimer, "Assessing driving simulator validity: a comparison of multimodal smartphone interactions across simulated and field environments," Transportation Research Record: Journal of the Transportation Research Board, vol. 2672, no. 37, pp. 164-171, 2018.

[139] B. Bartin, K. Ozbay, and H. Yang, "Evaluation framework for mobile ticketing applications in public transit: a case study," IET Intelligent Transport Systems, vol. 12, no. 9, pp. 1166$1173,2018$.

[140] O. Oviedo-Trespalacios, M. M. Haque, M. King, and S. Washington, "Should I text or call here? A situation-based analysis of drivers' perceived likelihood of engaging in mobile phone multitasking: mobile phone multitasking engagement," Risk Analysis, vol. 38, no. 10, pp. 2144-2160, 2018.

[141] N. Hajiheydari and M. Ashkani, "Mobile application user behavior in the developing countries: a survey in Iran," Information Systems, vol. 77, pp. 22-33, 2018.

[142] J. Hong and P. V. Thakuriah, "Examining the relationship between different urbanization settings, smartphone use to access the Internet and trip frequencies," Journal of Transport Geography, vol. 69, pp. 11-18, 2018.

[143] A. Douglas, B. Lubbe, and A. van Rooyen, "Business travellers' use of mobile travel applications: a generational analysis," Information Technology \& Tourism, vol. 18, no. 1-4, pp. 113-132, 2018.

[144] B. Assemi, H. Jafarzadeh, M. Mesbah, and M. Hickman, "Participants' perceptions of smartphone travel surveys," Transportation Research Part F: Traffic Psychology and Behaviour, vol. 54, pp. 338-348, 2018.

[145] A. Gupta, N. Dogra, and B. George, "What determines tourist adoption of smartphone apps?: an analysis based on the UTAUT-2 framework," Journal of Hospitality and Tourism Technology, vol. 9, no. 1, pp. 50-64, 2018.

[146] L. Lalicic and C. Weismayer, "Being passionate about the mobile while travelling," Current Issues in Tourism, vol. 21, no. 8, pp. 950-963, 2018.

[147] M. J. Kim, C.-K. Lee, and M. Bonn, "Obtaining a better understanding about travel-related purchase intentions among senior users of mobile social network sites," International Journal of Information Management, vol. 37, no. 5, pp. 484-496, 2017.

[148] J. Fang, Z. Zhao, C. Wen, and R. Wang, "Design and performance attributes driving mobile travel application engagement," International Journal of Information Management, vol. 37, no. 4, pp. 269-283, 2017.

[149] J. E. Dickinson, J. F. Hibbert, V. Filimonau et al., "Implementing smartphone enabled collaborative travel: routes to success in the tourism domain," Journal of Transport Geography, vol. 59, pp. 100-110, 2017.

[150] A. Aluri, "Mobile augmented reality (MAR) game as a travel guide: insights from Pokémon GO," Journal of Hospitality and Tourism Technology, vol. 8, no. 1, pp. 55-72, 2017.

[151] C. F. Mang, L. A. Piper, and N. R. Brown, "The incidence of smartphone usage among tourists," International Journal of Tourism Research, vol. 18, no. 6, pp. 591-601, 2016.

[152] Y. Qiao, X. Zhao, J. Yang, and J. Liu, "Mobile big-data-driven rating framework: measuring the relationship between human mobility and app usage behavior," IEEE Network, vol. 30, no. 3, pp. 14-21, 2016.

[153] I. P. Tussyadiah and D. Wang, "Tourists' attitudes toward proactive smartphone systems," Journal of Travel Research, vol. 55, no. 4, pp. 493-508, 2016.

[154] T. Schoenherr, "Mobile devices and applications for supply chain management: process, contingency, and performance effects," Transportation Journal, vol. 55, no. 4, p. 333, 2016.

[155] E. Sadeghvaziri, M. B. Rojas, and X. Jin, "Exploring the potential of mobile phone data in travel pattern analysis," Transportation Research Record: Journal of the Transportation Research Board, vol. 2594, no. 1, pp. 27-34, 2016.

[156] J. Lu, Z. Mao, M. Wang, and L. Hu, "Goodbye maps, hello apps? Exploring the influential determinants of travel app adoption," Current Issues in Tourism, vol. 18, no. 11, pp. 1059-1079, 2015. 
[157] B. Meng, M.-H. Kim, and Y.-H. Hwang, "Users and nonusers of smartphones for travel: differences in factors influencing the adoption decision," Asia Pacific Journal of Tourism Research, vol. 20, no. 10, pp. 1094-1110, 2015.

[158] C.-Y. Tsai, "An analysis of usage intentions for mobile travel guide systems," African Journal of Business Management, vol. 4, no. 13, pp. 2962-2970, 2010.

[159] N. Mohd Suki and N. Mohd Suki, "Flight ticket booking app on mobile devices: examining the determinants of individual intention to use," Journal of Air Transport Management, vol. 62, pp. 146-154, 2017.

[160] A. M. Dastjerdi, S. Kaplan, J. de Abreu e Silva, O. Anker Nielsen, and F. Camara Pereira, "Use intention of mobilitymanagement travel apps: the role of users goals, technophile attitude and community trust," Transportation Research Part A: Policy and Practice, vol. 126, pp. 114-135, 2019.

[161] G. Zhu, K. K. F. So, and S. Hudson, "Inside the sharing economy: understanding consumer motivations behind the adoption of mobile applications," International Journal of Contemporary Hospitality Management, vol. 29, no. 9, pp. 2218-2239, 2017.

[162] C. L. Hsu and J. C. C. Lin, "A study of the adoption behaviour for in-car GPS navigation systems," International Journal of Mobile Communications, vol. 8, no. 6, p. 603, 2010.

[163] S.-Y. Lin, P.-J. Juan, and S.-W. Lin, “A TAM framework to evaluate the effect of smartphone application on tourism information search behavior of foreign independent travelers," Sustainability, vol. 12, no. 22, p. 9366, 2020.

[164] M. Meireles and P. J. G. Ribeiro, "Digital platform/mobile app to boost cycling for the promotion of sustainable mobility in mid-sized starter cycling cities," Sustainability, vol. 12, no. 5, p. 2064, 2020.

[165] K. S. Asitha and H. L. Khoo, "Incentivised travel and mobile application as multiple policy intervention for mode shift," KSCE Journal of Civil Engineering, vol. 24, no. 10, pp. 3074-3091, 2020.

[166] B. S. di Teulada and I. Meloni, "Individual Persuasive Ecotravel Technology, a mobile persuasive application for implementing voluntary travel behaviour change programmes," IET Intelligent Transport Systems, vol. 10, no. 4, pp. 237-243, 2016.

[167] D. Jiménez, S. Hernández, J. Fraile-Ardanuy, J. Serrano, R. Fernández, and F. Álvarez, "Modelling the effect of driving events on electrical vehicle energy consumption using inertial sensors in smartphones," Energies, vol. 11, no. 2, p. 412, 2018.

[168] K. Suh, T. Smith, and M. Linhoff, "Leveraging socially networked mobile ICT platforms for the last-mile delivery problem," Environmental Science \& Technology, vol. 46, no. 17, pp. 9481-9490, 2012.

[169] R. A. dos Reis, S. Grant-Muller, R. Lovelace, and F. Hodgson, "Different people, different incentives? Examining the public acceptance of smartphone-based persuasive strategies for sustainable travel using psychographic segmentation," International Journal of Sustainable Transportation, vol. 2020, pp. 1-21, 2020.

[170] M. Bagheri, M. N. Mladenović, I. Kosonen, and J. K. Nurminen, "Analysis of potential shift to low-carbon urban travel modes: a computational framework based on high-resolution smartphone data," Sustainability, vol. 12, no. 15 , p. 5901,2020

[171] B.-J. Tang, X.-Y. Li, B. Yu, and Y.-M. Wei, "How app-based ride-hailing services influence travel behavior: an empirical study from China," International Journal of Sustainable Transportation, vol. 14, no. 7, pp. 554-568, 2020.

[172] G. Tavmen, "Data/infrastructure in the smart city: understanding the infrastructural power of citymapper app through technicity of data," Big Data \& Society, vol. 7, no. 2, Article ID 205395172096561, 2020.

[173] P. Zhao, D. Liu, Z. Yu, and H. Hu, "Long commutes and transport inequity in China's growing megacity: new evidence from Beijing using mobile phone data," Travel Behaviour and Society, vol. 20, pp. 248-263, 2020.

[174] H. Zhang, J. Chen, W. Li, X. Song, and R. Shibasaki, "Mobile phone GPS data in urban ride-sharing: an assessment method for emission reduction potential," Applied Energy, vol. 269, p. 115038, 2020.

[175] M. Noussan and S. Tagliapietra, "The effect of digitalization in the energy consumption of passenger transport: an analysis of future scenarios for Europe," Journal of Cleaner Production, vol. 258, p. 120926, 2020.

[176] O. I. Asensio, K. Alvarez, A. Dror, E. Wenzel, C. Hollauer, and S. Ha, "Real-time data from mobile platforms to evaluate sustainable transportation infrastructure," Nature Sustainability, vol. 3, no. 6, pp. 463-471, 2020

[177] M. Bagheri, M. N. Mladenovic, I. Kosonen, J. K. Nurminen, C. Roncoli, and A. Ylä-Jääski, "A computational framework for revealing competitive travel times with low-carbon modes based on smartphone data collection," Journal of Advanced Transportation, vol. 2020, pp. 1-20, 2020.

[178] F. Cellina, R. Castri, J. V. Simão, and P. Granato, "Cocreating app-based policy measures for mobility behavior change: a trigger for novel governance practices at the urban level," Sustainable Cities and Society, vol. 53, p. 101911, 2020.

[179] F. Cellina, D. Bucher, F. Mangili, J. Veiga Simão, R. Rudel, and M. Raubal, "A large scale, app-based behaviour change experiment persuading sustainable mobility patterns: methods, results and lessons learnt," Sustainability, vol. 11, no. 9, p. 2674, 2019.

[180] O. Roider, S. Wegener, J. Stark, P. Judmaier, F. Michelberger, and A. Barberi, "Merging virtual world with real-life behavior: a concept for a smartphone app to influence young people's travel behavior," Transportation Research Record: Journal of the Transportation Research Board, vol. 2673, no. 4, pp. 241-250, 2019.

[181] A. Mehdizadeh Dastjerdi, S. Kaplan, J. de Abreu e Silva, O. A. Nielsen, and F. C. Pereira, "Participating in environmental loyalty program with a real-time multimodal travel app: user needs, environmental and privacy motivators," Transportation Research Part D: Transport and Environment, vol. 67, pp. 223-243, 2019.

[182] B. Huang, T. Fioreze, T. Thomas, and E. Van Berkum, "Multinomial logit analysis of the effects of five different appbased incentives to encourage cycling to work," IET Intelligent Transport Systems, vol. 12, no. 10, pp. 1421-1432, 2018.

[183] S. Di Dio, M. La Gennusa, G. Peri, G. Rizzo, and I. Vinci, "Involving people in the building up of smart and sustainable cities: how to influence commuters' behaviors through a mobile app game," Sustainable Cities and Society, vol. 42, pp. 325-336, 2018.

[184] H. Zhang, X. Song, T. Xia et al., "Battery electric vehicles in Japan: human mobile behavior based adoption potential analysis and policy target response," Applied Energy, vol. 220, pp. 527-535, 2018.

[185] V. Astarita, G. Guido, D. Mongelli, and V. P. Giofrè, “A cooperative methodology to estimate car fuel consumption by 
using smartphone sensors," Transport, vol. 30, no. 3, pp. 307-311, 2015.

[186] W. Brazil and B. Caulfield, "Does green make a difference: the potential role of smartphone technology in transport behaviour," Transportation Research Part C: Emerging Technologies, vol. 37, pp. 93-101, 2013.

[187] S. Castellanos, "Delivering modal-shift incentives by using gamification and smartphones: a field study example in Bogota, Colombia," Case Studies on Transport Policy, vol. 4, no. 4, pp. 269-278, 2016.

[188] J. Jariyasunant, M. Abou-Zeid, A. Carrel et al., "Quantified traveler: travel feedback meets the cloud to change behavior," Journal of Intelligent Transportation Systems, vol. 19, no. 2, pp. 109-124, 2015.

[189] E. Anagnostopoulou, J. Urbančič, E. Bothos et al., "From mobility patterns to behavioural change: leveraging travel behaviour and personality profiles to nudge for sustainable transportation," Journal of Intelligent Information Systems, vol. 54, no. 1, pp. 157-178, 2020.

[190] F. Cellina, D. Bucher, J. Veiga Simão, R. Rudel, and M. Raubal, "Beyond limitations of current behaviour change apps for sustainable mobility: insights from a user-centered design and evaluation process," Sustainability, vol. 11, no. 8, p. 2281, 2019.

[191] H. Zhang, X. Song, Y. Long et al., "Mobile phone GPS data in urban bicycle-sharing: layout optimization and emissions reduction analysis," Applied Energy, vol. 242, pp. 138-147, 2019.

[192] M. Bopp, D. Sims, S. A. Matthews, L. S. Rovniak, E. Poole, and J. Colgan, "There's an app for that: development of a smartphone app to promote active travel to a college campus," Journal of Transport \& Health, vol. 3, no. 3, pp. 305-314, 2016.

[193] M. Rezae, D. McMeekin, T. Tan, A. Krishna, and H. Lee, "Evaluating the effectiveness of an autism-specific public transport app for individuals on the autism spectrum: a pilot study," Disability and Rehabilitation: Assistive Technology, vol. 2020, pp. 1-16, 2020.

[194] C. Dobbins and S. Fairclough, "Signal processing of multimodal mobile lifelogging data towards detecting stress in real-world driving," IEEE Transactions on Mobile Computing, vol. 18, no. 3, pp. 632-644, 2019.

[195] J. Weber, M. Azad, W. Riggs, and C. R. Cherry, "The convergence of smartphone apps, gamification and competition to increase cycling," Transportation Research Part F: Traffic Psychology and Behaviour, vol. 56, pp. 333-343, 2018.

[196] H.-C. Chin, X. Pang, and Z. Wang, "Analysis of bus ride comfort using smartphone sensor data," Computers, Materials \& Continua, vol. 60, no. 2, pp. 455-463, 2019.

[197] Y. Yang, S. Li, K. Zhang et al., "How the daily smartphone is associated with daily travel, physical activity, and self-perceived health: evidence from 2017 national household travel survey," Journal of Aging and Physical Activity, vol. 28, no. 5, pp. 740-748, 2020.

[198] S. R. Müller, H. Peters, S. C. Matz, W. Wang, and G. M. Harari, "Investigating the relationships between mobility behaviours and indicators of subjective well-being using smartphone-based experience sampling and GPS tracking," European Journal of Personality, vol. 34, no. 5, pp. 714-732, 2020.

[199] D. Q. Nguyen-Phuoc, O. Oviedo-Trespalacios, T. Nguyen, and $\mathrm{D}$. N. Su, "The effects of unhealthy lifestyle behaviours on risky riding behaviours-a study on app-based motorcycle taxi riders in Vietnam," Journal of Transport \& Health, vol. 16, p. 100666, 2020.

[200] H. Haddad and A. de Nazelle, "The role of personal air pollution sensors and smartphone technology in changing travel behaviour," Journal of Transport \& Health, vol. 11, pp. 230-243, 2018.

[201] R. Goodspeed, X. Yan, J. Hardy et al., "Comparing the data quality of global positioning system devices and mobile phones for assessing relationships between place, mobility, and health: field study," JMIR mHealth and uHealth, vol. 6, no. 8, p. e168, 2018.

[202] A. Ek, C. Alexandrou, C. Delisle Nyström et al., "The smart city active mobile phone intervention (SCAMPI) study to promote physical activity through active transportation in healthy adults: a study protocol for a randomised controlled trial," BMC Public Health, vol. 18, no. 1, p. 880, 2018.

[203] E. Dons, T. Götschi, M. Nieuwenhuijsen et al., "Physical activity through sustainable transport approaches (PASTA): protocol for a multi-centre, longitudinal study," BMC Public Health, vol. 15, no. 1, p. 1126, 2015.

[204] D. Q. Nguyen-Phuoc, C. De Gruyter, H. A. Nguyen, T. Nguyen, and D. Ngoc Su, "Risky behaviours associated with traffic crashes among app-based motorcycle taxi drivers in Vietnam," Transportation Research Part F: Traffic Psychology and Behaviour, vol. 70, pp. 249-259, 2020.

[205] M. Won, A. Shrestha, K.-J. Park, and Y. Eun, "SaferCross: enhancing pedestrian safety using embedded sensors of smartphone," IEEE Access, vol. 8, pp. 49657-49670, 2020.

[206] L. T. Truong and H. T. T. Nguyen, "Mobile phone related crashes among motorcycle taxi drivers," Accident Analysis \& Prevention, vol. 132, p. 105288, 2019.

[207] D. Q. Nguyen-Phuoc, H. A. Nguyen, C. De Gruyter, D. N. Su, and V. H. Nguyen, "Exploring the prevalence and factors associated with self-reported traffic crashes among app-based motorcycle taxis in Vietnam," Transport Policy, vol. 81, pp. 68-74, 2019.

[208] J. Warren, J. Lipkowitz, and V. Sokolov, "Clusters of driving behavior from observational smartphone data," IEEE Intelligent Transportation Systems Magazine, vol. 11, no. 3, pp. 171-180, 2019.

[209] L. Zhang, B. Cui, M. Yang, F. Guo, and J. Wang, "Effect of using mobile phones on driver's control behavior based on naturalistic driving data," International Journal of Environmental Research and Public Health, vol. 16, no. 8, p. 1464, 2019.

[210] A. Farnham, S. Ziegler, U. Blanke, E. Stone, C. Hatz, and M. A. Puhan, "Does the DOSPERT scale predict risk-taking behaviour during travel? A study using smartphones," Journal of Travel Medicine, vol. 25, no. 1, 2018.

[211] D. C. Schwebel, J. Severson, Y. He, and L. A. McClure, "Virtual reality by mobile smartphone: improving child pedestrian safety," Injury Prevention, vol. 23, no. 5, p. 357, 2017.

[212] O. Oviedo-Trespalacios, M. King, M. M. Haque, and S. Washington, "Risk factors of mobile phone use while driving in Queensland: prevalence, attitudes, crash risk perception, and task-management strategies," PLoS One, vol. 12, no. 9, Article ID e0183361, 2017.

[213] S. Park and I. P. Tussyadiah, "Multidimensional facets of perceived risk in mobile travel booking," Journal of Travel Research, vol. 56, no. 7, pp. 854-867, 2017.

[214] X. Delclòs-Alió, O. Marquet, and C. Miralles-Guasch, "Keeping track of time: a Smartphone-based analysis of 
travel time perception in a suburban environment," Travel Behaviour and Society, vol. 9, pp. 1-9, 2017.

[215] A. Marzuoli, E. Boidot, E. Feron, and A. Srivastava, "Implementing and validating air passenger-centric metrics using mobile phone data," Journal of Aerospace Information Systems, vol. 16, no. 4, pp. 132-147, 2019.

[216] Y. Lu and S. Velipasalar, "Autonomous footstep counting and traveled distance calculation by mobile devices incorporating camera and accelerometer data," IEEE Sensors Journal, vol. 17, no. 21, pp. 7157-7166, 2017.

[217] V. S. C. Tunn, E. A. van den Hende, N. M. P. Bocken, and J. P. L. Schoormans, "Digitalised product-service systems: effects on consumers' attitudes and experiences," Resources, Conservation and Recycling, vol. 162, p. 105045, 2020.

[218] Y. Xu, J. Li, J. Xue, S. Park, and Q. Li, “Tourism geography through the lens of time use: a computational framework using fine-grained mobile phone data," Annals of the Association of American Geographers, vol. 111, no. 5, pp. 1-25, 2021.

[219] A. Bwambale, C. F. Choudhury, S. Hess, and M. S. Iqbal, "Getting the best of both worlds: a framework for combining disaggregate travel survey data and aggregate mobile phone data for trip generation modelling," Transportation, vol. 48, no. 5, pp. 2287-2314, 2020.

[220] F. Li, X. Wang, B. Niu, H. Li, C. Li, and L. Chen, "Exploiting location-related behaviors without the GPS data on smartphones," Information Sciences, vol. 527, pp. 444-459, 2020.

[221] H. Kim and D. Sohn, "The urban built environment and the mobility of people with visual impairments: analysing the travel behaviours based on mobile phone data," Journal of Asian Architecture and Building Engineering, vol. 19, no. 6, pp. 731-741, 2020.

[222] D. Gillis, S. Gautama, C. Van Gheluwe, I. Semanjski, A. J. Lopez, and D. Lauwers, "Measuring delays for bicycles at signalized intersections using smartphone GPS tracking data," ISPRS International Journal of Geo-Information, vol. 9, no. 3, p. 174, 2020.

[223] S. Jamal and M. A. Habib, "Smartphone and daily travel: how the use of smartphone applications affect travel decisions," Sustainable Cities and Society, vol. 53, p. 101939, 2020.

[224] J. Liang, X. Zhang, and H. Yan, "Evaluating the impacts of parking app services on travellers' choice behaviour and traffic dynamics," Promet-Traffic \& Transportation, vol. 32, no. 2, pp. 179-191, 2020.

[225] T. E. Glasgow, H. T. K. Le, E. Scott Geller, Y. Fan, and S. Hankey, "How transport modes, the built and natural environments, and activities influence mood: a GPS smartphone app study," Journal of Environmental Psychology, vol. 66, p. 101345, 2019.

[226] M. Du, L. Cheng, X. Li, and J. Yang, "Investigating the influential factors of shared travel behavior: comparison between app-based third taxi service and free-floating bike sharing in Nanjing, China," Sustainability, vol. 11, no. 16, p. 4318, 2019.

[227] M. Elhamshary, M. Youssef, A. Uchiyama, A. Hiromori, H. Yamaguchi, and T. Higashino, "CrowdMeter: gauging congestion level in railway stations using smartphones," Pervasive and Mobile Computing, vol. 58, p. 101014, 2019.

[228] A. Ghose, H. E. Kwon, D. Lee, and W. Oh, "Seizing the commuting moment: contextual targeting based on mobile transportation apps," Information Systems Research, vol. 30, no. 1, pp. 154-174, 2019.

[229] A. Rodriguez-Valencia, D. Paris, and J. Cala, "Mobile internet applications: implications for taxi driver behavior and operations," Transportation Planning and Technology, vol. 43, no. 5, pp. 463-474, 2020.

[230] L. Zhong, S. Sun, R. Law, and L. Yang, "Investigate tourist behavior through mobile signal: tourist flow pattern exploration in Tibet," Sustainability, vol. 12, no. 21, p. 9125, 2020.

[231] M. Sester, "Analysis of mobility data-a focus on mobile mapping systems," Geo-Spatial Information Science, vol. 23, no. 1, pp. 68-74, 2020.

[232] W. Zong and J. Zhang, "Use of smartphone applications and its impacts on urban life: a survey and random forest analysis in Japan," Sustainable Cities and Society, vol. 49, p. 101589, 2019.

[233] K. B. Manrodt, J. L. Kent, and R. S. Parker, "Operational implications of mobile communications in the motor carrier industry," Transportation Journal, vol. 42, no. 3, pp. 50-58, 2003.

[234] J.-P. Rodrigue, "The distribution network of Amazon and the footprint of freight digitalization," Journal of Transport Geography, vol. 88, p. 102825, 2020

[235] M. Ghahramani, M. Zhou, and G. Wang, "Urban sensing based on mobile phone data: approaches, applications, and challenges," IEEE/CAA Journal of Automatica Sinica, vol. 7, no. 3, pp. 627-637, 2020.

[236] S. Guo, C. Song, T. Pei et al., "Accessibility to urban parks for elderly residents: perspectives from mobile phone data," Landscape and Urban Planning, vol. 191, p. 103642, 2019.

[237] O. Lindhiem, C. B. Bennett, D. Rosen, and J. Silk, "Mobile technology boosts the effectiveness of psychotherapy and behavioral interventions: a meta-analysis," Behavior Modification, vol. 39, no. 6, pp. 785-804, 2015.

[238] A. Aguiléra, C. Guillot, and A. Rallet, "Mobile ICTs and physical mobility: review and research agenda," Transportation Research Part A: Policy and Practice, vol. 46, no. 4, pp. 664-672, 2012.

[239] B. Blanc, M. Figliozzi, and K. Clifton, "How representative of bicycling populations are smartphone application surveys of travel behavior?" Transportation Research Record: Journal of the Transportation Research Board, vol. 2587, no. 1, pp. 78-89, 2016.

[240] C. Lamsfus, D. Wang, A. Alzua-Sorzabal, and Z. Xiang, "Going mobile: defining context for on-the-go travelers," Journal of Travel Research, vol. 54, no. 6, pp. 691-701, 2015.

[241] T. Schwanen, "Beyond instrument: smartphone app and sustainable mobility," European Journal of Transport and Infrastructure Research (EJTIR), vol. 15, no. 4, p. 16, 2015.

[242] F. Dal Fiore, P. L. Mokhtarian, I. Salomon, and M. E. Singer, "“Nomads at last"? A set of perspectives on how mobile technology may affect travel," Journal of Transport Geography, vol. 41, pp. 97-106, 2014.

[243] T. Line, J. Jain, and G. Lyons, "The role of ICTs in everyday mobile lives," Journal of Transport Geography, vol. 19, no. 6, pp. 1490-1499, 2011.

[244] A. Amey, J. Attanucci, and R. Mishalani, "Real-time ridesharing: opportunities and challenges in using mobile phone technology to improve rideshare services," Transportation Research Record: Journal of the Transportation Research Board, vol. 2217, no. 1, pp. 103-110, 2011.

[245] L. Budd and T. Vorley, "Airlines, apps, and business travel: a critical examination," Research in Transportation Business \& Management, vol. 9, pp. 41-49, 2013.

[246] D. Ettema, "Apps, activities and travel: an conceptual exploration based on activity theory," Transportation, vol. 45, no. 2, pp. 273-290, 2018. 
[247] S. Gössling, "ICT and transport behavior: a conceptual review," International Journal of Sustainable Transportation, vol. 12, no. 3, pp. 153-164, 2018.

[248] E. Anagnostopoulou, E. Bothos, B. Magoutas, J. Schrammel, and G. Mentzas, "Persuasive technologies for sustainable mobility: state of the art and emerging trends," Sustainability, vol. 10, no. 7, p. 2128, 2018.

[249] A. Andersson, L. Winslott Hiselius, and E. Adell, "Promoting sustainable travel behaviour through the use of smartphone applications: a review and development of a conceptual model," Travel Behaviour and Society, vol. 11, pp. 52-61, 2018.

[250] S. A. Shaheen, E. Martin, A. Cohen, A. Musunuri, A. Bhattacharyya, and I. Berkeley, "Mobile apps and transportation: a review of smartphone apps and a study of user response to multimodal traveler information," 2016, https://rosap.ntl.bts.gov/view/dot/32921.

[251] K. B. Ooi, F. E. Foo, and G. W. H. Tan, "Can mobile taxi redefine the transportation industry? A systematic literature review from the consumer perspective," International Journal of Mobile Communications, vol. 16, no. 3, pp. 341359, 2018.

[252] B. T. H. Yen, C. Mulley, and M. Burke, "Gamification in transport interventions: another way to improve travel behavioural change," Cities, vol. 85, pp. 140-149, 2019.

[253] Y. Li and Y. Yu, "The use of freight apps in road freight transport for $\mathrm{CO} 2$ reduction," European Transport Research Review, vol. 9, no. 3, p. 36, 2017.

[254] E. Mellegard, S. Moritz, and M. Zahoor, "Origin/destinationestimation using cellular network data," in Proceedings of the 2011 IEEE 11th International Conference on Data Mining Workshops, pp. 891-896, Vancouver, Canada, December 2011.

[255] Y. Yamada, A. Uchiyama, A. Hiromori, H. Yamaguchi, and T. Higashino, "Travel estimation using Control Signal Records in cellular networks and geographical information," in Proceedings of the 2016 9th IFIP Wireless and Mobile Networking Conference (WMNC), pp. 138-144, Colmar, France, July 2016.

[256] J. Amankwah-Amoah, "Emerging economies, emerging challenges: mobilising and capturing value from big data," Technological Forecasting and Social Change, vol. 110, pp. 167-174, 2016.

[257] J. Spinney and W.-I. Lin, “Are you being shared? Mobility, data and social relations in Shanghai's public bike sharing 2.0 sector," Applied Mobilities, vol. 3, no. 1, pp. 66-83, 2018.

[258] D. Corsar, C. Cottrill, M. Beecroft et al., "Build an app and they will come? Lessons learnt from trialling the GetThereBus app in rural communities," IET Intelligent Transport Systems, vol. 12, no. 3, pp. 194-201, 2018.

[259] O. Cats and E. Jenelius, "Dynamic vulnerability analysis of public transport networks: mitigation effects of real-time information," Networks and Spatial Economics, vol. 14, no. 34, pp. 435-463, 2014. 